\title{
Whole Organ Engineering: Approaches, Challenges, and Future Directions
}

\author{
Sogu Sohn 1,2, Maxwell Van Buskirk ${ }^{2,3}$, Michael J. Buckenmeyer ${ }^{2,4,5}$, Ricardo Londono ${ }^{2}$ \\ and Denver Faulk 2 ,* \\ 1 Biomedical Engineering, University of Texas at Austin, 107 W Dean Keeton, Austin, TX 78712, USA; \\ sogus@andrew.cmu.edu \\ 2 Organoid Therapeutics, Inc., 372 North Craig St., Pittsburgh, PA 15213, USA; \\ mvanbusk@andrew.cmu.edu (M.V.B.); mjb235@pitt.edu (M.J.B.); londonor@upmc.edu (R.L.) \\ 3 Biomedical Engineering, Carnegie Mellon University, 5000 Forbes Ave, Pittsburgh, PA 15213, USA \\ 4 Bioengineering Department, University of Pittsburgh, 3700 O'Hara St., Pittsburgh, PA 15260, USA \\ 5 McGowan Institute for Regenerative Medicine, 450 Technology Drive, Pittsburgh, PA 15219, USA \\ * Correspondence: dmf62@pitt.edu; Tel.: +1-786-371-0124
}

Received: 6 May 2020; Accepted: 16 June 2020; Published: 22 June 2020

Featured Application: The specific application of this review article is for the advancement of commercially translatable technologies in the field of whole organ engineering.

\begin{abstract}
End-stage organ failure remains a leading cause of morbidity and mortality across the globe. The only curative treatment option currently available for patients diagnosed with end-stage organ failure is organ transplantation. However, due to a critical shortage of organs, only a fraction of these patients are able to receive a viable organ transplantation. Those patients fortunate enough to receive a transplant must then be subjected to a lifelong regimen of immunosuppressant drugs. The concept of whole organ engineering offers a promising alternative to organ transplantation that overcomes these limitations. Organ engineering is a discipline that merges developmental biology, anatomy, physiology, and cellular interactions with enabling technologies such as advanced biomaterials and biofabrication to create bioartificial organs that recapitulate native organs in vivo. There have been numerous developments in bioengineering of whole organs over the past two decades. Key technological advancements include (1) methods of whole organ decellularization and recellularization, (2) three-dimensional bioprinting, (3) advanced stem cell technologies, and (4) the ability to genetically modify tissues and cells. These advancements give hope that organ engineering will become a commercial reality in the next decade. In this review article, we describe the foundational principles of whole organ engineering, discuss key technological advances, and provide an overview of current limitations and future directions.
\end{abstract}

Keywords: whole organ engineering; extracellular matrix; biologic scaffolds; constructive remodeling; tissue remodeling; wound healing; decellularization; genetic engineering; tissue engineering; regenerative medicine; stem cells

\section{Introduction}

End-stage organ failure affects millions of people every year in the United States alone. Heart disease is particularly burdensome to the healthcare system, having been the leading cause of death in the US for the past decade, with heart failure contributing to 1 in 8 deaths in 2017 according to the Center for Disease Control [1]. Chronic kidney disease had a prevalence of $15 \%$ in the US, or approximately 37 million people, in 2019, with over 661,000 of these individuals having progressed 
to end-stage renal disease (ESRD) [2,3]. While various therapies can mitigate the progression of organ disease, autologous organ transplantation is currently the gold standard for end-stage organ failure [4]. Kidney transplants have been shown to improve patient survival when compared to dialysis, and transplants of the liver, heart, and lungs are life-saving [4]. However, while organ transplantation is an immensely beneficial technology, it is significantly limited by the shortage of transplantable organs. From 1991 to 2019, the number of individuals on the waiting list for organ transplants has rapidly increased from around 23,000 to over 112,000 , while the numbers of organ donors and organ transplant operations performed have increased relatively marginally from 7000 to 19,000 and 15,000 to 39,000 , respectively [5]. Figure 1 graphically represents the disparity resulting from different growth rates of individuals in need of organs and number of transplants performed. This large difference in organ supply and demand contributes to the deaths of 20 people every day who are on a transplant waitlist [5]. In addition to the disparity between number of donors and number of patients on the waitlist, the shortage of transplantable organs is exacerbated by the fact that on average, only $0.3 \%$ of individuals die in a way that makes their organs viable for transplantation, as deaths caused by old age, disease, or severe physical trauma can compromise the functionality of organs [5]. International organ transplantation data illustrates a similar trend globally. A report in 2017 by the Global Observatory on Donation and Transplantation found that data comprising 82 member states, whose data was representative of approximately $75 \%$ of the global population, showed that the 139,024 organ transplantations performed that year barely accommodated $10 \%$ of the global need [6].

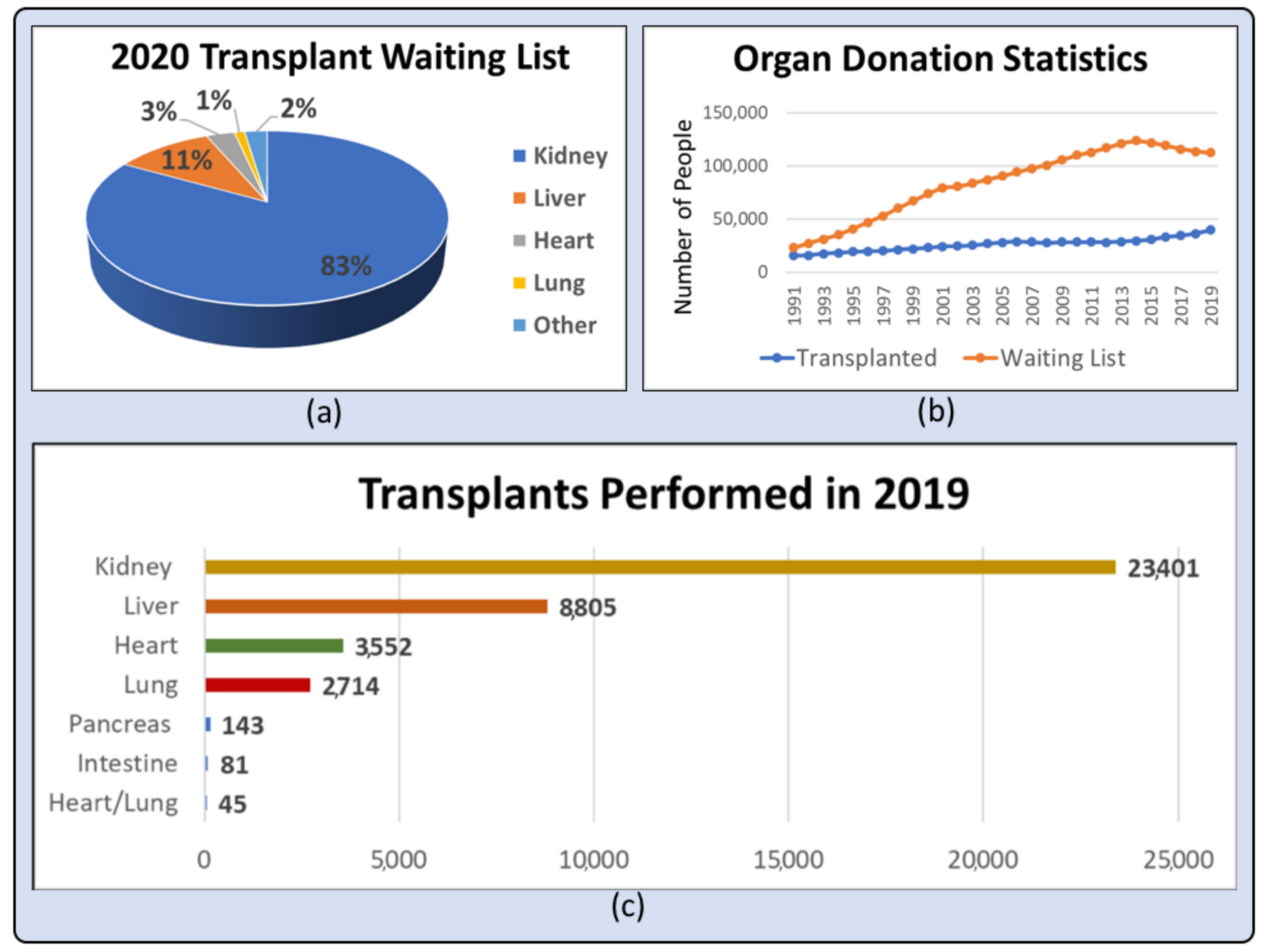

Based on OPTN data as of April, 2020

Figure 1. In the US: (a) Most needed organs on the transplant waitlist and their respective percentages in 2020 as of March, (b) number of individuals on the waitlist and the number of transplantations performed from 1991 to 2019, and (c) number of transplants performed in 2019 organized by organ. 
Even if a viable organ is successfully excised, patient-donor compatibility concerns can prevent transplantation from occurring [7]. A blood type match is necessary for all organs, but other congruencies such as body size as well as geographical location of donor and patient can affect the viability of some organs, limiting the potential for transplantation [7]. Furthermore, individuals who are fortunate enough to receive a life-saving organ transplant must remain on immunosuppressant drugs indefinitely to prevent organ rejection via an immune response [8]. Rejection occurs because transplanted organs are attacked by the patient's immune system due to the patient's immune cells' identifying the antigens present on the surface of the donated organ cells as foreign [8]. Immunosuppressant drugs decrease the likelihood of transplant rejection; however, they also put the transplant recipient at risk. Patients become more susceptible to infections at the site of surgery while the wounds have yet to heal, and for the rest of their lives, they are more susceptible to bacterial pathogens and viruses [9]. Due to a shortage of organs available, limitations of autologous organ transplants, and an increase in the population of individuals that require organ transplants, there remains an unmet clinical need for novel therapies to treat patients with end-stage organ failure. In this review, we discuss the recent advancements in the field of tissue engineering, specifically using the extracellular matrix (ECM) to create naturally derived bioengineered organs, which may be used as an alternative to autologous organ transplantation.

\section{Review Methodology}

\subsection{Literature Search}

A short list of field leaders in whole organ engineering was compiled based on the authors with the highest number of citations reported in Google Scholar. This list was developed by using the search query "(organ type) whole organ engineering" in Google Scholar, where the organ types included heart, kidney, bladder, lung, liver, gastrointestinal, skin, and pancreas. The search results were filtered for only scientific articles and the authors with the most citations across multiple articles for a specific organ type were considered leaders in their respective field. Journal articles and reviews by these various field leaders were found using Google Scholar, PubMed, Web of Science, and various other peer-reviewed journal databases and search engines using the author name and "whole organ engineering" as the search queries and categorized based on their topic, subfield, and relevance. Additional articles found during these searches that cited or were cited by the field leaders as well as related articles with high citation numbers but not written by field leaders were also sorted into the aforementioned categories. All of the articles used in this review were also analyzed in depth to determine if they were part of the field of whole organ engineering. This determination was made based on if the article described a technique for partially or completely reconstructing a whole organ using tissue-derived materials and/or cells for use in organ repair and transplantation, which is what constitutes the field of whole organ engineering. The organization of the various literature in this search formed the structure of the review that is further outlined in this section.

\subsection{History of Whole Organ Engineering}

An author search using the list of field leaders was conducted using PubMed to determine the earliest articles by these authors that were both in the field of whole organ engineering and had a significant impact on the field. Using the search query of author name and "whole organ engineering", the search results were sorted by increasing publishing year, and non-review articles with more than 50 citations were analyzed to determine if they were part of the whole organ engineering field using the aforementioned method in Section 2.1. These high-impact papers were organized in chronological order by their publishing date to construct a timeline of the whole organ engineering, starting from the oldest relevant papers in the field to the late 2000's. The first section features the birth of the field and foundational technologies of whole organ engineering while the latter sections go into more 
detail about the foundational technologies mentioned and their lasting impact on the field of whole organ engineering.

\subsection{Approaches to Engineering Whole Organs}

During the literature search process mentioned in Section 2.1, publications that had methodologies in common were put in categories. For reviews that cited a number of research reports utilizing a specific methodology, the reports utilizing those methods were also categorized. Once these papers were sorted, the most relevant approaches, determined by the total number of citations of the research reports that fell into each category, became the basis of Section 4: Approaches to Engineering Whole Organs. The first succeeding section talks about high-level categorization of approaches and the latter sections go into the most relevant approaches in the field of whole organ engineering that fall into these high-level categories.

\subsection{Recent Developments and Accomplishments}

The field of whole organ engineering is quite broad as it encompasses a number of different sub-fields representing whole organ engineering for specific organs and organ systems. As mentioned previously in Section 2.1, the literature search regarding the current state-of-the-art in whole organ engineering was broken up into the following categories for each organ or organ system: heart, liver, kidney, lungs, pancreas, bladder, skin, and gastrointestinal. Articles in these various subfields found during the literature search that were published in 2013 or later were organized by their relevance in the field. This relevance was roughly calculated as the number of citations divided by the number of years since publishing. Obviously, an article published 5 years ago will have more citations than an article published last year even if they are similar in their novelty and importance. Using this relevance score, approximately 3-7 articles in each subfield with the highest relevance are discussed in chronological order by publishing date in each of the subsections of Section 5: Recent Development and Accpomplishments, which consist of the aforementioned organ subfields.

Table 1, summarizing the leading publications in the field for each of the last ten years, was put together using the Web of Science ${ }^{\mathrm{TM}}$ search tool from Clarivate Analytics ${ }^{\mathrm{TM}}$. The basic search tool was used with the search terms "whole organ engineering" and "tissue engineering" for topic and the publication dates were restricted to 2010-2020. The search results were put in order based on descending number of citations and then the results were categorized by their publication year, starting with 2010 and ending with 2020. The paper listed for each year with the greatest number of citations that was not a review was analyzed to determine if it was encompassed by the field of whole organ engineering. If it was determined to not be in the field of whole organ engineering, the article with the next greatest number of citations was analyzed. This continued until an article was determined to be relevant to the field of whole organ engineering and was chosen for the table. This was repeated for each individual year between 2010 and 2020 until a complete list of the leading whole organ engineering papers from every year was completed. Each paper was analyzed in depth to produce a summary and determine the paper's impact on the field of whole organ engineering.

\subsection{Supporting Technological Advancements}

A number of publications found during the literature search, both research reports and review articles, mentioned supporting technologies that contributed to the success of their approach. These papers were categorized based on the supporting technologies that they mentioned and the supporting technologies that were most relevant, which had the greatest number of citations across papers that described it and formed the basis of Section 6: Supporting Technological Advancements.

\subsection{Major Challenges and Barriers to Market}

Similar to the supporting technological advances section, a number of publications found during the literature search, both research reports and review articles, mentioned the major challenges 
and obstacles that needed to be overcome before their approach could become marketable or clinically viable. These papers were categorized based on the challenges and obstacles that they mentioned and the challenge/barrier categories that were most relevant, which contained the greatest number of papers, and formed the basis of Section 7: Major Challenges and Barriers to Market.

In addition, as engineered whole organs intrinsically fall under the purview of government bodies in charge of regulating medical devices, online resources and databases provided by the Food and Drug Administration (FDA) were used to examine the regulations that whole organ engineering would need to adhere to. For information regarding regulations in the US, documents provided by the federal government such as the Code of Federal Regulations provided more information than peer-reviewed articles, resulting in online federal resources being cited in lieu of such articles.

\section{History of Whole Organ Engineering}

\subsection{Origin and Foundational Technologies}

The concept of tissue engineering as a field came into being in the late 1980s, both largely established and popularized as a distinct field of research by Joseph Vacanti and Robert Langer from the former's research article describing the use of polymer networks as cellular scaffolds and their combined review article outlining the scientific basis and future directions of the novel field $[10,11]$. Tissue engineering was primarily established to develop technology to overcome the limits of organ transplantation, with whole organ engineering being a recent development in the field that has shown the potential to do so [12]. The fundamental concept of tissue engineering is to utilize a biocompatible material to form a scaffold onto which cells can adhere to and grow on in order to form tissue. The term "biomaterial" encompasses a vast array of materials from glass to hydrogels, with the best biomaterial for engineering a tissue being whichever best mimics the tissue type. For example, porous tantalum metallic scaffolds are suitable for engineering bone tissue due to their mechanical strength [13]. In comparison, polymeric biomaterials have been used to develop soft-tissue organs, which are particularly relevant for patients with end-stage organ failure. These biomaterials have been used in a range of tissue engineering applications due to their material chemistry allowing for versatility in fabrication methods $[13,14]$. Synthetic polymers, such as poly(glycolic acid) (PGA), poly(lactic acid) (PLA), and poly(lactic acid-co-glycolic acid) (PLGA), are the most well-studied and commonly used synthetic biomaterials in tissue engineering due to their in vivo degradability by hydrolysis and their biocompatibility [15]. However, while synthetic polymers can be formed into desirable scaffold structures, they are inadequate for engineering functional tissue because their lack of cell adhesion sites reduces their ability to direct cell activity [16-18]. Natural polymers are another category of polymeric biomaterials that are often used for engineering soft tissue. Alginate is a natural polymer widely used in tissue engineering due to its abundance, gelation characteristics, hydrophilicity, and physical similarities to native ECM [19-21] . However, alginate does not have cell-binding side groups, making it difficult for cells to adhere to it, and has been found to limit cell migration and proliferation [22]. As the goal of whole organ engineering is to direct cellular activity to form tissue and organ constructs, the native biomaterial scaffolding of the ECM seems best suited for tissue and organ engineering purposes.

Some of the most significant early research showing the feasibility of tissue engineering was performed by Joseph P. Vacanti in 1988, where he showed the ability of biocompatible synthetic polymers to act as scaffold material for cells to be seeded onto [12]. Vacanti also demonstrated the value of ECM proteins by coating the polymers with collagen and fibronectin to increase cell adhesion [12]. Additionally, Vacanti identified limitations of tissue engineering research that would need to be addressed to engineer larger scale tissue, such as tissue size being restricted by the distance gas and nutrients can diffuse. Vacanti and Langer helped to further establish tissue engineering as a distinct field with their review article in 1993 by presenting research that used biomaterial scaffolds as cell adhesion substrates for various cell types of each germ layer, such as nerve bridges composed 
of polymers laden with Schwann cells [10]. In 1997, Eschenhagen et al. utilized embryonic chick cardiomyocytes and a collagen gel to generate one of the first contractile engineered cardiac tissues, demonstrating the viability of tissue engineering to be applied to cardiac regenerative medicine [23]. In 2000, Fink et al., developed a bioreactor to stimulate cardiac tissue to produce more mature tissue, with bioreactors having since become a crucial component of many tissue engineering approaches [24]. Figure 2 summarizes notable discoveries over the last four decades that have greatly contributed to whole organ engineering.

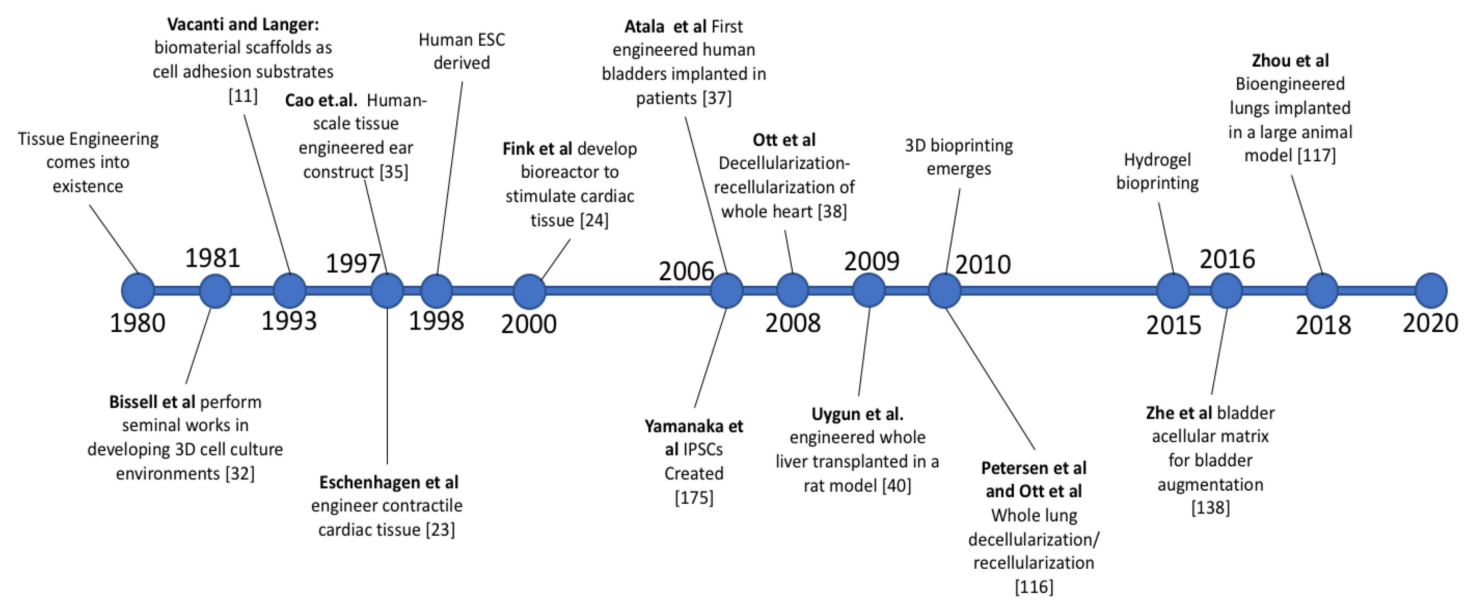

Figure 2. Timeline of significant discoveries that have contributed to and advanced the field of whole organ engineering.

\subsection{Extracellular Matrix}

In Langer and Vacanti's 1993 review publication, they identified research that fell under the umbrella of the new field of tissue engineering [10]. Several of these early tissue engineering works incorporated ECM components by coating synthetic scaffolds with ECM proteins [25]. In 1992, Mooney et al. performed experiments to assess what ECM proteins and what configurations of those proteins could dictate hepatocyte behavior, specifically whether the cells would proliferate or differentiate [25]. They found that rather than a specific protein or scaffold geometry, it was the ECM density that determined hepatocyte fate by modulating cell shape. Other work has shown ECM-derived scaffolds to be capable of directing cell adhesion and tissue growth according to the scaffold orientation [26,27]. Badylak and colleagues demonstrated the repair capacity of engineered ECM scaffolds in their 1999 publication outlining their studies on the effects of using porcine small intestinal submucosa (SIS) ECM scaffolds as grafts for goat anterior cruciate ligament injuries [27]. The implanted SIS graft underwent significant remodeling by the host and thus notably increased in strength to have similar failure force as a patellar tendon autograft implanted in the same goat, with histology revealing no difference in inflammatory cell behavior in the two grafts [27]. Similar remodeling and regenerative mechanisms driven by ECM scaffolds have been observed in animal heart models as well [28]. van Amerongen et al. implanted type I collagen scaffolds into injured left ventricles of mice, which were degraded by matrix metalloproteinases and replaced by vascularized ECM [28]. The ECM's capacity for cell adhesion and ability to direct cell behavior and integrate with host tissue after implantation, as it did in these studies, have caused it to be one of the foremost scaffold biomaterials used in tissue engineering.

The ECM is a complex and dynamic composite network of biopolymers laden with bioactive compounds like growth factors, and is responsible for providing tissue with its structural properties as well as directing cellular activity $[29,30]$. The main components of the ECM are collagens, elastin, proteoglycans, hyaluronic acid, laminin, and fibronectin. There are at least 16 types of collagen, the most abundant being collagen type I, II, and III, which are interstitial collagens that bundle together to form fibrils with high tensile strength, type IV which forms X-shaped units that connect 
to form a fibrous network and is abundant in the basement membrane, and type VI which plays a role in connecting interstitial collagen to cells and aids in cell adhesion to the ECM [30,31]. Elastin is a protein that is highly elastic, with a higher amount of elastin in tissue resulting in greater mechanical compliance [30]. Proteoglycans are proteins with several glycosaminoglycan (GAG) side chains and are highly hydrophilic, allowing tissue to retain water [30]. Hyaluronic acid (HA) is a GAG that is not covalently attached to a protein, distinguishing it from proteoglycans, though HA does share proteoglycans' hydrophilicity and tissue hydrating role [30]. Laminin, which has 15 isoforms at the time this article was written, is an adhesion protein that is plentiful in the basal lamina, binding to other ECM molecules such as collagen and other laminins [30]. Fibronectin is another adhesion protein that contains binding domains for collagens, integrins, and heparin sulfate [30]. These biomolecules form the composite network of the ECM to provide a substrate, which directs how cells grow and interact with one another, with changes in the ECM structure changing how cells within it interact. One way in which changes in the ECM affect cell behavior is in the formation of new tissue. ECM growth and remodeling is how tissue is formed during embryogenesis, with different tissue ECM's serving as microenvironments that can direct cell differentiation into various cell lineages and induce changes in cell shape that promote certain cell activity [32-34]. ECM remodeling also plays a role in tissue regeneration, with differences between human adult and fetal ECM composition playing a large role in directing tissue remodeling to enable fetal cutaneous wounds to heal without scars [32-34]. Because of the ECM's well-documented roles in the development and maintenance of tissue through both structural and physiological activity, ECM molecules have become the foundation of whole organ engineering.

\subsection{Growing Human Tissue In Vivo}

Cao and Vacanti et al., published results of a tissue engineering approach for engineering cartilage tissue in the shape of an ear on the back of mice that would become known as the "Vacanti mouse". A scaffold comprising PGA, a material often used in surgical meshes, was formed into the shape of an ear using a plaster mold cast from an alginate construct of a 3 year old's ear [35]. The PGA ear scaffolds were then placed in tissue culture dishes and seeded with a chondrocyte cell suspension derived from bovine calf cartilage [35]. Athymic mice had one chondrocyte-laden scaffold each placed in a subcutaneous pocket on their backs, with half the mice in the experimental group receiving an external stent in the shape of the ear and the other half receiving no stent [35]. Twelve weeks post-implantation, the scaffolds were removed, with histological analysis revealing that the stented implants had maintained the shape of the original mold and maintained shape during the last eight weeks of implantation after the stent was removed, while the unstented implants shrank and became distorted. Both groups had new cartilage that was synthesized by the chondrocytes [35].

\subsection{Autologous Engineered Tissues for Organ Resuscitation}

In 2006, Atala et al., published their results from a study after implanting engineered bladders in human patients with end-stage bladder disease from 1999 to 2018, expanding upon previous animal studies that demonstrated the feasibility of implanting de novo bladder tissue in dogs [36]. Patient cells from bladder biopsy samples were expanded into muscle and urothelial cell cultures and then seeded on either a collagen matrix derived from decellularized bladder submucosa or a composite bioscaffold composed of collagen and PGA, with some scaffolds of each type being covered in an omental wrap [37]. The seeded scaffolds were incubated for 3 or 4 days before implantation, wherein the engineered bladder was anastomosed to the native bladder with sutures and fibrin glue [37]. Postoperative analysis was done for up to five years to assess maximum capacity pressure, leakage, and histology of tissue samples. These assessments found that the composite bioscaffold wrapped in omentum had the best result in improving patients' urinary continence and bladder compliance and capacity, which was concluded to be because the PGA provided greater structural durability than collagen alone, and the omental wrap enhanced vascularization of the implants [37]. Though an entire organ was not 
engineered ex vivo, the engineered bladder tissue was structurally and physiologically interchangeable with any segment of the rest of the bladder and was able to regenerate function of failing organs and improve quality of life for patients.

\subsection{First Engineered Beating Heart}

The first instance of whole organ engineering was in a heart model via the perfusion decellularization and then recellularization of a whole rat heart by Ott et al. in 2008 [38]. Ott utilized a modified Langendorff heart perfusion apparatus, originally developed by Oscar Langendorff in 1895, to perfuse cadaveric rat hearts with different detergent solutions [38]. The decellularized hearts maintained their ECM architecture, vascular patency, and valve geometry. Decellularized hearts were recellularized with neonatal cardiac cells or aortic endothelial cells via intramural injection and perfusion respectively, and maintained in a bioreactor, demonstrating electrical and mechanical activity and genetic expression of mature cardiac tissue 8 days after seeding [38]. Maintaining native ECM structure to generate a contractile whole heart with mature, functional cells further substantiated the vital role that the structure and composition of the ECM plays in tissue regeneration. As the first decellularized whole-organ construct, Ott's work opened up a new area of tissue engineering, with the techniques he developed laying the foundation for whole heart engineering through de-cell/re-cell technology.

\subsection{Early Success in Animal Studies for Liver Engineering}

The key factor in the liver's distinctive regenerative ability is its unique ECM, which allows for tissue growth and remodeling in a manner that re-establishes the tissue composition of healthy, mature liver tissue after injury [39]. Because of this, utilizing ECM-derived bioscaffolds is crucial for the successful engineering of liver tissue. Similar to the previously mentioned first instance of whole heart engineering, the first engineered whole liver was developed through leveraging native liver ECM architecture via de-cell/re-cell methods. In 2009, Uygun et al. adapted Ott et al.'s heart de-cell/re-cell method for the decellularization and recellularization protocols for rat livers [40]. After decellularization, histological analysis found that $>97 \%$ of DNA was removed and dye perfusion revealed the decellularized vascular network to be intact, while perfusion recellularization successfully seeded rat hepatocytes onto the vasculature, from which they migrated into the tissue and populated the liver construct [40]. Immunostaining of the liver revealed the cells to be producing hepatic enzymes and proteins at levels similar to that of functional livers. Furthermore, Uygun assessed early graft function of the recellularized livers via auxiliary transplantation in rats and ex vivo whole blood perfusion, finding hepatic function and cellular function preserved with minimal signs of ischemic damage [40]. Uygun et al.'s work further established whole organ engineering's viability as a substitute to transplantation by demonstrating the ability of an entirely engineered whole organ to be viable and functional after implantation.

\subsection{Academic and Industry Pioneers}

Many leaders in the field of whole organ engineering have already been mentioned in this review. Dr. Harald C. Ott, MD, is a pioneer in the field of whole organ decellularization and recellularization, with his work with the heart model being the first engineered whole organ [38]. Dr. Stephen F. Badylak, DVM, PhD, MD is a leader in regenerative medicine research with a focus on the importance of the ECM microenvironment in engineering functional tissue, including through whole organ engineering. Dr. Basak E. Uygun, PhD is an expert in liver decellularization, having been the first to adapt Ott's decellularization for the liver and having been the corresponding author on many recent liver engineering techniques that utilize ECM as a bioscaffold [41,42]. Dr. Anthony Atala, $\mathrm{MD}$, was responsible for one of the earliest demonstrations of engineered organs being able to revive failing organ functionality by implanting engineered bladders in human patients, and has since performed research that has shown him and his group to be experts and pioneers in organ engineering 
and regenerative medicine, especially in urinary organ engineering [37]. Dr. Alejandro Soto-Gutierrez, $\mathrm{MD}, \mathrm{PhD}$, has done extensive work in whole liver engineering and particularly in using pluripotent stem cells to revive hepatic function of liver scaffolds sourced from cadavers [43]. In addition to the leaders in academia, there are many companies, often founded on the basis of technology developed through academia, that have made great strides in both research and endeavors to commercialize engineered organs and tissue. Miromatrix is developing engineered whole liver and kidney products derived from de-cell/re-cell technology, helping to lay the groundwork for the commercialization of engineered organs [44]. Tissue Regeneration Systems is using three-dimensional (3D)-printed scaffolds to generate bone grafts and implants for skeletal reconstruction, leveraging the ability of engineered organ constructs to be customized based on patients' needs [45]. Rokit Healthcare utilizes bioprinting technology to generate soft tissue constructs, aiming to generate patient-compatible grafts and organs [46]. Combined, these leaders in academia and industry are laying the foundation for greater development and future commercialization of whole organ technologies that could eliminate the disparity between the number of transplantable organs available and the individuals in need of transplants.

\section{Approaches to Engineering Whole Organs}

\subsection{High-Level Strategies}

There are two major approaches to whole organ engineering: (1) top-down construction and (2) bottom-up construction (Figure 3). The concept of top-down engineering is to develop scaffolds that direct cells to form functional tissues. Macroscopic, or even whole organ scaffolds, are seeded with one or many cell types, where a combination of scaffold remodeling and self-assembly leads to the formation of a complex 3D tissue or whole organ [47-49]. In contrast, bottom-up engineering utilizes the smallest component elements of tissue, such as collagen molecules, as building blocks and combines them to assemble a larger construct [50-55]. Similar to erecting a building by adding one brick at a time, bottom-up engineering methods are designed to control and organize the interaction of cells with each other and their surroundings. Using stem cell engineering, it is possible to utilize a single building block, human pluripotent stem cells (hPSCs), to engineer constructs such as organoids, and organ-specific functional tissue through a bottom-up approach [56].

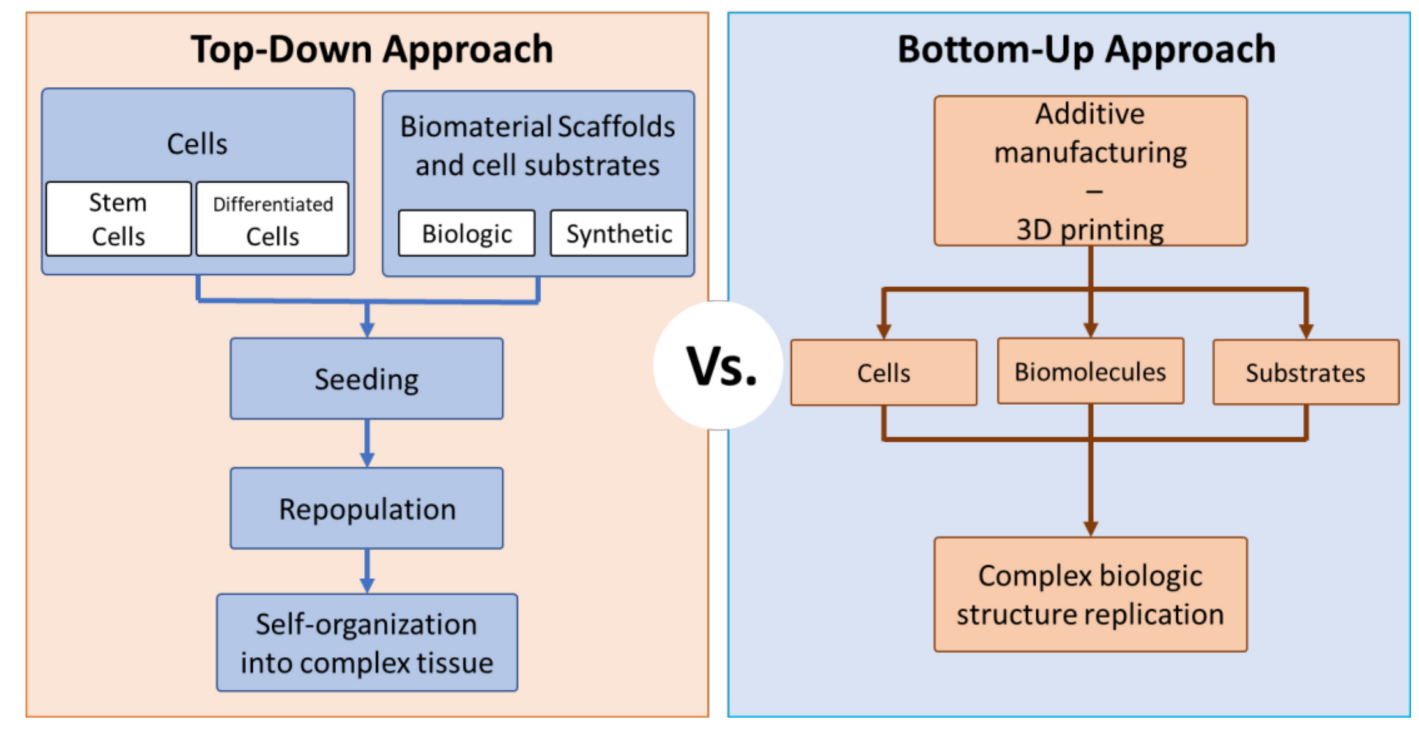

Figure 3. Comparison of top-down and bottom-up whole organ engineering strategies.

The most complete top-down methods use whole organs from donor or cadaveric sources that are decellularized and then re-seeded with autologous somatic cells, induced pluripotent stem cells 
(iPSCs), or adult stem cells $[43,48,57]$. Using the native matrix composition and complex architecture to regenerate functional whole organs has distinct advantages over other whole organ regeneration methods and is the closest to becoming a clinically viable substitution for organ transplantation. Despite these advantages, several barriers to clinical translation of this approach, such as efficient methods of maturing cells seeded on decellularized organs as well as proliferating cells to physiologically viable numbers for recapitulating whole organ structure and function, still need to be overcome [56]. Bottom-up approaches require fabrication methods that can replicate the bulk structure of organs along with their complex internal geometries. A bottom-up method that has been widely used due to its ability to generate complex constructs is additive manufacturing, or 3D printing [51]. Three-dimensional (3D) bioprinting is useful in bottom-up whole organ engineering because organ structure can be replicated using highly accurate models generated from imaging technology like magnetic resonance imaging (MRIs) and can print constructs with internal tubular networks resembling vasculature ranging from arterial to capillary diameters [58]. Additionally, the bioinks used in 3D bioprinting can be derived from native ECM molecules, such that printed organ constructs have an internal microenvironment conducive to cell adhesion and proliferation $[51,58,59]$. Bioprinted organ structures have demonstrated the ability to replicate specific organ functions. However, increasing the structural and physiological complexity of organ constructs to be able to produce multiple organ functions in a single engineered organ remains a challenge.

A significant barrier impeding the creation of whole organs is developing an organ engineering approach that incorporates functional angiogenesis, lymphangiogenesis, and neurogenesis within a single organ or organ system [60]. All of these components must be present in an engineered whole organ, but no one has successfully accomplished this yet.

\subsection{Building Organs from Cadaveric Organs (De-Cell/Re-Cell)}

While the shortage of donated organs is the primary reason why some individuals can remain on a transplant waitlist for years, compatibility between donor and recipient is a concern as well. Blood type and body size are the most apparent limiting factors [7]. Even when all other compatibility factors are satisfied, the fact that the DNA of the donated organ's cells are different from the recipient's DNA means there is risk of an immune response and organ rejection. However, top-down organ engineering methods can be used to overcome these limits. Cadaveric and potentially even animal organs (e.g., porcine) can be engineered to have the donor's cellular material removed while retaining the ECM structure and biochemical properties, then repopulated to house non-immunogenic cells. This not only removes concerns of blood type but also eliminates the concern of the organ recipient's immune system recognizing and attacking the donor's cells in the organ [47,61-64]. Removing the native cells, or decellularization, commonly involves perfusing the vasculature of an organ with surfactant and enzyme solutions to kill cells via lysis, then rinsing the vasculature with a saline solution which is often paired with mechanical stimulation to remove cells embedded in tissue [47,61-64]. This process can produce an organ construct with the structural properties and biochemical markers of the native organ while removing native DNA, and thus has the potential to mitigate the immune response to cadaveric human and even animal organs. Repopulating the acellular cadaveric construct, or recellularization, involves perfusing the vasculature of the organ with a cell solution and maintaining the construct in a bioreactor to promote cell adhesion and proliferation [40,62,65-67]. The decellularization will have removed cells but left the ECM with its structural and biochemical properties, maintaining a microenvironment conducive to cell adhesion and growth. If the cells used are sourced from the patient or from cells genetically engineered to be immune-compatible, then the cell-laden organ construct will not elicit an adaptive immune response upon implantation. Because of the potential for decellularization/recellularization procedures to remove the immunogenicity of tissue, using cadaveric human and animal organs as sources for ECM scaffold generation has gained prominence in whole organ engineering research $[56,60,61,68,69]$. 
ECM and decellularization techniques are a promising method of personalized organ production. Early work in advancing decellularization approaches focused on maintenance of whole organ function after decellularization in animal models [70] as well as allogenic clinical studies [71] without seeding cells in vitro. For example, Ott et al. investigated the mechanical properties and ECM composition of the rat heart, while Macchiarini et al. characterized clinical factors relevant towards allogeneic tracheal tissue implantation $[37,68]$. Such results were limited in scope since they used mechanical tests to determine decellularized organ function rather than evaluating the regenerative capacity of the scaffolds. Further investigation by Ott et al., tested the regenerative capacity of a rat heart in vitro by recellularizing the rat heart with a coronary perfusion bioreactor and then subjecting it to a periodic electrical stimulus [38]. They found that their approach resulted in the decellularized heart regaining roughly $2 \%$ of the pump function of native adult rat hearts and $25 \%$ of the pump function of a 16-week fetal human heart, and even responded to doses of phenylephrine with increased contractility as a native heart would [70]. Engineered whole human trachea allografts were analyzed before and 3 months after implantation, and it was found that physiological function was restored in the graft and that the grafting procedure resulted in the reversal of airway obstruction [71].

\subsection{Building Organs from Synthetic Biomaterials}

Synthetic scaffolds and grafts are a tool for structural engineering and development of implantable organs. In the late 1970s and early 1980s, many researchers and scientists began developing new approaches to shaping polymers into sophisticated and complex structures, which resembled the needed architectures of whole organs and tissues. The manufacturing methods resulted in reproducible and tunable scaffolding materials for the purpose of tissue regeneration. Synthetic polymer scaffolds have the advantage of possessing high mechanical strength, adjustable porosity and surface area, reproducible manufacturing, and engineered surface chemistry [14].

The starting scaffolding is the essential foundation for building functional and viable whole organs. This is because the three-dimensional anatomic orientation must be similar to naturally occurring scaffolding in order to be successful. With synthetic biomaterials, these key scaffolding characteristics and attributes can be engineered to the specific application they are being designed for. Standard synthetic scaffolding designs have typically consisted of surgical meshes, polymer fibers, sponges, foams, sheets, and various other configurations. Different types of synthetic biomaterial scaffolds, including microsphere scaffolds, porous scaffolds, hydrogel scaffolds, fibrous scaffolds, polymer-bioceramic composite scaffolds, and acellular scaffolds, are all used in these various applications [14].

\subsection{Building Organs from Biohybrid Materials}

Biohybrid materials are materials comprising both biological and non-biological components. Biohybrid materials have been explored in tissue engineering applications due to certain drawbacks of tissue scaffolds comprised solely of biological components. For instance, the ECM plays a vital role in directing native cell activity and ECM-derived proteins have demonstrated the same ability in engineered constructs [26,27]. However, objects made of only ECM proteins can rapidly degrade or are not structurally robust enough to replicate the activity of compliant, matrix-dense tissues [72]. Synthetic polymers can be tuned on the molecular level to generate a scaffold with desired bulk properties to mimic native ECM's mechanical properties [72]. Pairing the cellularly interactive ECM proteins with the mechanical and degradation tunability of synthetic polymers can produce biocompatible scaffolds that can be modified to suit remodeling of different tissue types.

There are four types of commonly used biohybrid materials: (1) interwoven biological and non-biological fibers, (2) bilayers comprising distinct synthetic and ECM layers, (3) synthetic scaffolds seeded with cells that synthesize ECM in the scaffold, and (4) composite hydrogels. Interwoven synthetic and biological fibers are often formed using electrospinning, and electrospun biohybrid scaffolds have been implemented in engineering vascular grafts [72-75]. Co-spinning synthetic and biological polymers allows for the production of independent and distinct fibers on the nanoscale, 
though the deposition of the fibers can be difficult to control and produce a random fiber orientation [76]. Fiber diameter can be modulated by controlling speed and charge of material deposition and can be adjusted to resemble native ECM both in its dimensions and structural properties [75,76]. Electrospun biohybrid scaffolds can also be designed with an adequately porous structure to allow for high cell infiltration and migration $[75,76]$.

In biohybrid bilayers, the synthetic and biological components are discrete components that are combined in layers [72]. Because the two materials are distinct constituents, generally, a biohybrid bilayer takes advantage of the properties of a primary material and uses a secondary material to provide support; for example, the primary material may be the synthetic layer to provide mechanical strength while the secondary biological layer provides key cell interactive cues [72,77]. Some bilayer materials utilize intact native tissue, such as the pericardium, due to its high ECM protein content, low cellularity, and mechanical properties, with a synthetic polymer layer surface crosslinked to the pericardium [78]. Three-dimensional printing is also a suitable bilayer manufacturing technique, as layer-by-layer fabrication is readily performed with a 3D printer [79].

For biohybrid materials in which the ECM component is produced by cells seeded on a synthetic polymer scaffold, the successful integration of ECM proteins depends on the ability of the synthetic component to allow high cell infiltration and promote cellular production of ECM [72]. Because these materials incorporate cells, decellularization of the material after adequate ECM synthesis is a critical step [72]. This type of biohybrid material may be particularly suitable for tissue-specific use if the cells used to fabricate the ECM in the scaffold can be sourced from the tissue site of interest, as the ECM produced by these cells will have the same composition as the native ECM [72].

Hydrogel blends are formed by combining ECM proteins and synthetic polymers prior to gelling the two to form a single, composite hydrogel. Polyethylene glycol (PEG) is often incorporated into biohybrid hydrogels due to its bioinert property, well understood tunable degradation mechanics, and high solubility in water [80]. Biohybrid functionality can be achieved by modifying PEG monomers with bioactive molecules or by physically entrapping them while still maintaining the tunability of its strength and degradation that can be achieved by controlled crosslinking [72,80,81]. In doing so, biohybrid hydrogels offer a way to incorporate different biomolecules such as ECM proteins into microenvironments with tunable mechanics to mimic the conditions of native tissue degradation and remodeling $[72,81]$.

\subsection{Three-Dimensional Bioprinting}

One of the more remarkable technological achievements and advancements in recent history is $3 \mathrm{D}$ printing $[50,82,83]$. Ultimately, one of the most impressive feats to arise from 3D printing has been the ability to print biological materials and then have those scaffolds seeded with living cells, which is commonly referred to as 3D bioprinting. This approach includes fundamentals from various fields, including tissue engineering, materials engineering, cellular biology, and advanced robotic printing $[53,84]$. Three-dimensional bioprinting is perhaps the most well-known bottom-up approach to tissue engineering in the public eye. Three-dimensional printing as a technology came about in 1981 when Hideo Kodama published his work on 3D plastic manufacturing using UV-cured photopolymers, which would later be developed into the 3D printing technique stereolithography by Charles Hull, which creates a print layer by layer via UV light hardening a solution from which the print is drawn out of $[85,86]$. Other 3D printing methods were developed later, including Fused deposition modeling (FDM), which is used in popular consumer plastic printers, in 1988, selective laser sintering in 1986, and selective laser melting in $1995[87,88]$.

Three-dimensional printing is attractive in whole organ engineering because its ability to generate custom and complex geometries has the potential to translate well into generating personalized organs for patients. The technology was first used in medical applications in the early 2000s for printing hard constructs such as bone implants and prosthetics [89]. Human-scale bone scaffolds have been generated using selective laser melting or sintering of materials like alloys and bioresorbable polymers [90,91]. 
Even more in its infancy than solid construct printing is soft construct printing to replicate soft tissue, done using inkjet, extrusion, or stereolithography (SLA) printing. Inkjet bioprinting uses electric, mechanical, or thermal stress to compress the bioink into a droplet as it is extruded [51].

Bioinks used in inkjet bioprinters are often composed of cells encapsulated in solubilized biopolymers such as collagen and fibrin that gel after extrusion, allowing for more homogeneous and controllable distribution of cells in an engineered tissue construct than when cells are seeded onto a scaffold, which can contribute to cell behavior better mimicking native functions [53,59]. Extrusion-based bioprinting utilizes FDM printing technology with a specialized extrusion head, often a syringe tip, to extrude a bioink comprising a structural solubilized biopolymer solution like alginate or collagen, a cell solution, or a combination of the two. Extrusion bioprinting can either use different bioinks as scaffolding and for cell delivery, build the scaffold and extruding cells into the scaffold, or utilize a composite bioink in which cells are laden within a structural biopolymer solution [58,92]. Similar to inkjet printing, extrusion printing's use of cell-laden bioink that is laid out in predetermined structures results in a more homogeneous and controlled cell distribution that is conducive to cell proliferation, tissue growth, and the recreation of native cell function [58]. SLA bioprinting is performed largely in the same manner as traditional SLA, using a photocurable pool of material from which a platform is lowered with a laser curing the material layer-by-layer [93]. Regardless of the 3D printing technique utilized, bioprinting soft tissue constructs is advantageous because of both the customizability and precision it provides. This precision is highly desirable in producing vascular networks within tissue constructs, as tissue size is otherwise limited by the distance which gas and nutrients can diffuse. The bottom-up approach of 3D bioprinting would allow for this limit to be overcome by generating whole organs with hollow networks built-in so that the construct is vascularized [51].

\subsection{Organoids}

Organoids are a tissue engineering technology that seeks to replicate native organ function in miniature fetal or adult organ-like structures. They have been used for more accurate disease modelling, toxicology and drug studies due to their greater similarity to native organs than more basic in vitro cultures, as well as tissue/organ replacement [94,95]. Organoids are also well suited to these applications as they can be developed from patient-derived cells, improving the accuracy of disease models or drug studies and mitigating the concern of an immunological response of tissue replacement. Patient-specific toxicology studies have been demonstrated to be a particularly useful application of organoids, as native organ physiology can be replicated and tested in vitro if the organoids are engineered using patient cells $[94,96]$. Cristobal et al., developed human colon organoids derived from both healthy and cancerous sections of colon from patients with colorectal cancer [94]. Using proteomic analysis of the organoids, Cristobal and colleagues were able to identify specific phenotypes in patients that could dictate their disease progression and ultimate clinical outcome, thus allowing a personalized treatment to be developed thanks to the organoids [94]. In 2016, Kim and colleagues demonstrated that organoids formed from pancreatic cells derived from human embryonic stem cells were capable of performing pancreatic endocrine functions in vitro and in vivo [95]. In vitro glucose stimulation of the pancreatic organoids induced release of insulin-containing vesicles, and implantation of the organoids into diabetic mice resulted in a decrease of blood glucose levels and insulin was detected in the transplant sites [95]. These results demonstrate the ability of organoids to replicate and even replace organ function, doing so autonomously in response to native physiological cues.

Organoid technology can potentially be utilized to advance whole organ research. Both areas of tissue engineering are concerned with addressing organ failure and regeneration, and both have similar challenges. The main technical challenge in the way of organoid development is engineering an organoid environment that provides the same structural support biochemical cues as the native environment. As the native ECM is intrinsically designed for such a purpose, utilizing native 
ECM components to engineer the organoid microenvironment is an approach that shows promise in addressing this challenge.

\section{Recent Developments and Accomplishments}

\subsection{Heart}

The quest of engineering a viable and functional whole-heart replacement via whole organ engineering necessitates the development of various approaches for cellular removal due to the high density, large mass, and anatomic complexity of the native human heart. Preclinical studies that utilize perfusion decellularization of rodent hearts have presented encouraging results, but applying this technique to larger animal models such as porcine and bovine that would translate to clinical use of this technique are still a challenge [38]. In a 2010 study conducted by Wainwright et al., a porcine heart was decellularized reproducibly and efficiently using retrograde aortic perfusion with a mixture of solvents, but reseeding this scaffold efficiently requires further research [97].

Decellularization and recellularization approaches are prevalent in whole heart engineering due to the heart's complex geometry and electromechanical functions making the native ECM architecture difficult to replicate in vitro. Guyette et al., expanded upon Ott et al.'s original whole heart decellularization work in 2008 according to standardized protocols developed in the Ott lab to decellularize donated human hearts, and successfully removed over $99 \%$ of double-stranded DNA, as determined by endonuclease perfusion [98]. Micro-computed tomography (CT) scans found no statistically significant difference in vascular density between cadaveric and decellularized cardiac matrix, though the decellularized hearts did have lower vascular densities, especially in the endocardium, showing that the decellularization process preserved vasculature but that full-depth vascular recruitment is more difficult in a decellularized heart [98]. The decellularized constructs were repopulated with cardiomyocytes derived from human iPSCs in a custom bioreactor. Analysis of cell activity revealed glucose consumption and lactate production that suggested metabolic activity, electrical stimulation produced visible contractions, and histological analysis showed over $90 \%$ cell viability, which indicated that coronary perfusion was providing adequate nutrition and gas exchange [98]. Taylor et al., utilized a porcine model, using de-cell/re-cell procedures on porcine hearts and then heterotopically implanting them in living pigs to leverage the body's natural ability to repopulate the scaffold to a greater extent than if only ex vivo recellularization were used [99]. The heterotopic hearts were rapidly endothelialized by host cells, which could potentially reduce clot formation after transplantation, which is a concern with the heart transplant process [99]. Using a decellularization approach to generate whole heart cell scaffolding is promising, but does have its challenges, as assessed in a study by Sanchez et al., which used the data from 39 heart decellularization procedures to identify critical troubleshooting points in the process [100].

Bottom-up heart engineering techniques, namely 3D bioprinting, are an alternative avenue of research for pursuing whole heart engineering without the challenges of de-cell/re-cell approaches [58,92]. Noor et al., developed a novel, personalized bioink fabrication method for extrusion bioprinting thick, vascularized cardiac tissue [92]. The personalized bioink was composed of thermoresponsive ECM hydrogel and cardiomyocytes derived from iPSCs, both of which were derived from omental tissue [92]. A sacrificial support material was used for printing, allowing complex geometries to be generated while the structure maintained its shape; thus, allowing cellularized cardiac patches with built-in vasculature and miniature hearts to be printed [92]. This technique's ability to generate vascularized constructs with complex geometry and its use of cellularized bioink derived from patient omentum, a readily available cell source, make it a promising approach to whole organ engineering. Another bottom-up approach to cardiac tissue engineering was published by Lee et al. in 2019 utilizing an improved version of their freeform reversible embedding of suspended hydrogels (FRESH) printing technique [54,58]. FRESH utilizes an extrusion bioprinter to print into a sacrificial gelatin microparticle coacervate that supports the extruded bioink as it crosslinks and solidifies and then is removed by melting the support 
at physiological temperatures $\left(37^{\circ} \mathrm{C}\right)$, allowing for complex geometries to be printed as one continuous construct using cell-laden bioinks, then removed from the support material in conditions unharmful to cells [54]. Lee and colleagues used FRESH and collagen bioink to print a human neonatal-scaled heart of a MRI-derived heart model, a 1:1 scale human tri-leaflet heart valve that was mechanically functional in an ex vivo pulsatile perfusion system, a perfusable vascular network with vessels as small as 100 microns, and a cardiac ventricle printed with an infill of cardiac cell bioink that demonstrated synchronized contractions along directional action potential propagation [58]. FRESH bioprinting demonstrates the capability to engineer tissue with properties needed to generate viable cardiac transplant tissue; however, more work must be done to be able to FRESH print these properties in a single construct, as the patient-specific geometry, vascularization, and functional cell population properties were achieved individually in separate constructs.

\subsection{Liver}

Bioengineering a whole liver has long been clinically appealing because of the liver's tremendous ability to regenerate and the therapeutic potential of transplanted livers, which are the current standard for treating end-stage liver disease. A focus of whole liver engineering has been research and development of an acellular tissue scaffold engineered from a whole liver, aiming to utilize the native structure to house parenchymal cells that will revive liver-specific functions. Uygun et al. published work demonstrating that perfusing rat livers with sodium dodecyl sulfate (SDS) solution followed by Triton X-100 solution through the hepatic portal vein resulted in the removal of cellular material, namely DNA, in the livers, while still retaining the native 3D ECM architecture and preserving the vascular architecture [40]. By recellularizing the acellular architecture with adult rat hepatocytes via their previously developed seeding protocol, Uygun and colleagues found that the hepatocytes remained viable for 5 days, with albumin and urea production levels during that time indicating that the cells were metabolically functional. The engineered livers were then heterotopically transplanted into rats, which demonstrated that engrafted hepatocytes were able to remain in their original attachment point and maintain their cellular morphology when exposed to blood flow from the host circulatory system, despite the resulting shear stress the circulation imparted on the cells. Furthermore, hepatic function such as secretion of albumin and urea as well as activity levels of CP450 were comparable to those of in vitro studies, which demonstrated the possibility for an engineered whole liver to function as a liver transplant in rats [40].

Baptista et al., also developed a bioengineered whole rat liver, in which human hepatic cells were successfully incorporated. Excised rat livers were perfusion decellularized using a solution of Triton X-100 mixed with ammonium hydroxide. The acellular liver scaffolds were then recellularized using human umbilical vein endothelial cells (HUVECs) and human fetal liver cells via perfusion of the preserved vascular network [63]. These rat livers cellularized with human cells were cultured in a bioreactor and displayed morphology and function resembling that of native liver tissue. The fetal liver cells and endothelial progenitor cells used were able to differentiate into mature endothelial and hepatic-specific cells. In 2015, Ko and colleagues successfully conjugated anti-endothelial cell antibodies to the inner wall of blood vessels before recellularizing decellularized porcine livers, demonstrating that this approach could generate functionality within the liver vascular network [101]. This approach enabled endothelial cells to homogenously attach to both larger blood vessels as well as capillaries, significantly reducing the extent to which platelet adhesion occurred once in vitro blood perfusion was performed. After vascularization, the bioengineered porcine livers were capable of withstanding the shear stress arising from blood flow and successfully avoid thrombosis after implantation into pigs. In another study by Hussein et al. in 2016, instead of using anti-endothelial cell antibodies, a heparin-gelatin mixture was incorporated to improve the attachment efficiency of endothelial cells as well as mitigate thrombus formation [102]. Using this methodology, bioengineered livers that underwent vascular network reconstruction were also implanted and studied in porcine models. 
In 2011, Soto-Gutierrez et al., used perfusion with enzymatic and non-SDS detergent solutions along with mechanical stimulation to decellularize whole rat livers, with analysis of the decellularized whole liver matrices revealing that in addition to preserving the structure and vasculature of the liver ECM, their decellularization process maintained ECM composition and presence of growth factors, which can often be eliminated during decellularization [42]. Soto-Gutierrez and colleagues found that the decellularized livers maintained about $50 \%$ and $40 \%$ of the hepatocyte growth factor (HGF) and basic fibroblast growth factor (bFGF) respectively, contained in native livers [42]. HGF and bFGF contribute to stimulation of epithelial cell proliferation and migration, angiogenesis, and wound healing in the liver, which contributed to the $>90 \%$ cell engraftment efficiency observed after recellularization with rat hepatocytes, with engrafted cells showing hepatic metabolic activity $[43,103,104]$. Other liver decellularization methods have leveraged the native ECM to improve patient-specific cell sourcing and reendothelialization of vascular networks in engineered whole livers [41,42,105]. Jaramillo et al. showed that the mechanical and physiological signals of decellularized liver ECM resulted in improved hepatic differentiation of human iPSCs when compared to the same protocol with Matrigel, improving prospects for patient-derived iPSCs to be used in patient-specific engineered livers [41]. Improved reendothelialization of decellularized livers was shown to result from the conjugation of the REDV cell binding domain of endothelial cells to an elastin-like peptide (ELP) by Devalliere et al. [42]. A different approach to reendothelialization of decellularized whole livers by Mao et al. used porcine umbilical cord-derived endothelial cells, resulting in maintenance of an intact vascular network after an extensive $72 \mathrm{~h}$ of ex vivo perfusion without thrombus formation, which can easily form when perfusing an organ for that long [103]. These studies represent successful, ongoing efforts to engineer functional vasculature within decellularized whole livers in order to recellularize them with functional hepatocytes and generate clinically applicable engineered livers.

\subsection{Kidney}

Whole kidney engineering has been performed through both top-down and bottom-up approaches. As is the case when engineering other whole organs, the use of a decellularized cadaveric kidney is a widespread approach to top-down kidney engineering [64,106-109]. Standard decellularization protocol utilizing SDS to remove cellular material is applicable to whole kidneys and is commonly used [64,106-109]. In 2013, Orlando and colleagues demonstrated the potential for top-down engineered kidneys to help reduce the disparity between organ supply and waitlisted individuals by engineering viable renal scaffolds from discarded human kidneys [106]. Kidneys are generally discarded for anatomical anomalies like atrophy or hardening of the renal vasculature, inflammation, or cortical necrosis, as well as prolonged ischemic storage [106]. Using SDS perfusion decellularization protocols, discarded human kidneys were found to maintain their ECM structure, vascular patency, and biochemical properties [106]. This research demonstrates the potential for whole organ engineering to lessen the organ recipient/donor disparity using readily available resources. Repopulation of acellular cadaveric kidney scaffolds has been demonstrated as well $[47,110,111]$. Ciampi et al., repopulated decellularized rat kidney constructs with human endothelial cells derived from iPSCs [111]. Endothelial cell infusion through the renal artery of the rat kidneys led to widespread, homogeneous distribution of endothelial cells along the inner walls of the vasculature [111]. Transmission and scanning electron microscopy revealed that fenestration only occurred in the glomerular capillaries, indicating that the rat ECM scaffold had modulated endothelial cell adhesion and phenotype [111]. These findings suggest that whole kidney engineering via a top-down approach can maintain kidney macro- and micro-structure and preserve biochemical properties of renal structures to direct cell adhesion and activity.

Additive manufacturing methods for kidney engineering have been utilized as well, and are showing promise in being able to replicate the internal architecture of the kidney [112-115]. Ali et al. published results of a novel ECM-derived, photo-crosslinkable bioink they had developed [112]. The bioink was derived from porcine kidneys that were perfusion decellularized with SDS, Triton-X 100, and nuclease enzymes, with the acellular ECM scaffold then being solubilized with acid, and the solution 
then methacrylated so that it could be photo-crosslinked using UV light [112]. Constructs were printed using the kidney-derived bioink with human kidney cells included, with the resulting printed constructs retaining structural properties of native kidney tissue, and the cells remaining viable over time and maturing [112]. More recently, Carreno-Galeano et al. utilized the same kidney-derived bioink to print ECM constructs laden with human kidney cells and implanted them in nude rats [115]. The constructs remained viable for two months, with comparisons of the implant site at the two-month timepoint to earlier times revealing that new tubular structures formed in the tissue around the implant, with human kidney cell markers detected in these new structures [115]. Host renal progenitor cell recruitment was observed in tissue surrounding acellular constructs that were implanted as well [115].

\subsection{Lungs}

Proper respiratory function is heavily dependent on lung tissue mechanics, due to the need for an ECM structure that promotes gas exchange and elasticity. Replication of native lung tissue mechanics has been accomplished via various decellularization approaches. The first experiments in which a whole bioengineered lung was created using decellularization and recellularization were published in 2010 by Ott et al. and Peterson et al. [48,116]. Due to the dependence of respiratory function on the compliance of lung tissue, it is crucial that engineered whole lungs retain the native lung tissue mechanics as much as possible after decellularization, as the process can damage native ECM in addition to removing cellular material. Because of this, decellularization protocols must be developed to be as harmless as possible to lung ECM. Various perfusion methods using detergent solutions such as SDS, Triton X-100, and CHAPS, as well as enzymatic solutions, have been studied in various animal and human models to determine effective decellularization methodologies [117-120]. However, decellularization protocols are not well standardized, and the optimal decellularization method is undefined. Early lung recellularization procedures were done via injection of primary pulmonary and endothelial cells, and related cell lines, into the trachea and pulmonary artery $[48,116]$. Restoring the ability of the lungs to perform their most primary function, gas exchange, requires reconstruction of the microstructures comprising the airways and blood vessels of a recellularized lung repopulated with epithelial and endothelial cells, respectively. To that end, recellularization has been approached via supplying endothelial cells and perivascular cells through the pulmonary artery and the pulmonary vein, while the airway is epithelialized via the bronchial system [48,116-120].

In 2018, Zhou et al., published their results of a large animal study in which they recellularized acellular porcine lung scaffolds with human airway progenitor cells and HUVECs [117]. The recellularized lung constructs were maintained in a bioreactor for 6 days to allow the seeded cells to mature. The humanized porcine lungs were then transplanted into pigs and perfused using the host's pulmonary circulation for $1 \mathrm{~h}$. It should be noted that the bioengineered lungs displayed reduced capabilities of gas exchange and mechanical compliance when compared to native lung tissue. Various groups have developed bioreactors for maintaining recellularized grafts in vitro, in which cellular differentiation or maturation can be facilitated via steady vascular perfusion and bronchial ventilation. These bioreactors are intended to mimic the physiological conditions native lung tissue is exposed to and thus enable cells to create an organ in vitro that resembles the native lung. For recellularization of acellular lung scaffolds, pulmonary cells are often derived from iPSCs because iPSCs can be autologously sourced and then expanded to the requisite cell population size needed to repopulate whole lungs [48,116-120].

Functional endothelialized pulmonary vasculature must be able to maintain a fluid-tight seal while still permitting the exchange of oxygen and carbon dioxide. Dr. Laura E. Niklason's group developed a successful protocol for seeding decellularized lung scaffolds with endothelial cells by perfusing cells into the lung microvasculature [116]. However, this method was not able to successfully generate an endothelial layer with barrier functionality and was susceptible to thrombosis. In a 2019 study, Niklason's group expanded upon their work in Yuan et al., 2019 by incorporating various small, bioactive molecules into the recellularization of decellularized lungs to determine if this would 
result in improved endothelial function [121]. They found that incorporating 8CPT-2Me-cAMP, an Epac-selective cyclic adenosine monophosphate analog, into the recellularization process resulted in superior endothelial barrier function within the recellularized lungs. HUVECs treated with this Epac agonist demonstrated improved barrier functionality that could be maintained for at least three days, as opposed to the five-hour-long effect resulting from other molecules Niklason and colleagues tested. Epac agonist treatment resulted in reorganization of actin structure, as well as an increase in continuity of the junction proteins VE-cadherin and ZO1. When actin polymerization was prevented, the effects of the Epac agonist were removed, substantiating a strong actin-mediated effect. In addition, iPSC-derived endothelial colony forming cells (ECFCs) treated with the Epac agonist displayed an increase in barrier function that was maintained for $>60 \mathrm{~h}$. The iPSC-ECFCs were shown to maintain their phenotype after being cultured in lung scaffolds for 5 days, as evidenced by their expression of the proteins CD31, eNOS, vWF, and VE-Cadherin. Niklason and colleagues' work shows that Epac-selective 8CPT-2Me-cAMP is a potentially useful tool in improving the functionality of engineered endothelium in bioengineered whole lungs, which is a vital component of whole lungs [121].

Nichols et al., also utilized decellularization and recellularization of porcine lungs to approach developing a bioengineered lung on a clinically relevant scale [122]. Using hydrogels laden with growth factor containing nanoparticles, Nichols and colleagues were able to promote improved cell adhesion to decellularized whole porcine lungs. These scaffolds were developed into bioengineered lungs by seeding them with autologous cells and showed vascular perfusion from collateral circulation after less than 2 weeks post-transplantation. The transplanted lungs could be aerated and contained a microbiome similar to that of native lung. One pig displayed no symptoms of respiratory issues when euthanized an entire 2 months after transplant. This work is a considerable advance in the lung tissue engineering field and demonstrated the viability of tissue-engineered lungs in the realm of clinical applications.

\subsection{Pancreas}

The pancreas is a heterogeneous organ that has both exocrine and endocrine functions. The exocrine function is performed by acinar cells, which secrete enzymes to aid in digestion. In contrast, endocrine activity is carried out by the islets of Langerhans, which produce hormones to regulate glucose levels within the blood. Pancreatic tissue transplantation is primarily used for patients with severe cases of type I diabetes (T1D), which eliminates the insulin-producing beta cells of the pancreas causing hyperglycemia. Inadequate control of blood glucose levels can lead to significant complications and may require an islet transplantation to restore beta cell function. However, there are a limited number of donor pancreata available, which currently makes this strategy unsustainable as a long-term treatment option for T1D. In addition to organ shortage, islet transplantation is associated with a significant loss of islets due to poor blood supply reducing the effectiveness of this therapy. Finally, this allogeneic cell source requires immunosuppression to avoid transplant rejection. To address these concerns, researchers are evaluating the efficacy of naturally derived acellular scaffolds to generate novel therapies for treating T1D.

Bioengineering the endocrine pancreas presents several challenges. One of these challenges is to replicate the islet cell niche, which consists of a unique three-dimensional ECM structure and vasculature embedded within a cluster of endocrine cells [123]. Top-down whole pancreas engineering methods have been developed to utilize native pancreatic ECM as a scaffold to support islet cell function [124-128]. Goh et al., used perfusion decellularization to obtain an acellular ECM scaffold from whole mouse pancreata and characterized both exocrine and endocrine function after reseeding the scaffold with acinar (AR42J) and mouse beta cells (MIN-6) [124]. Whole pancreata were harvested from Institute for Cancer Research (ICR) mice perfused through the pancreatic vasculature via the hepatic portal vein. Detergent-based solutions, $0.5 \%$ SDS and $1 \%$ Triton X-100, were used in tandem with nucleases to clear cellular components. Acellular pancreatic scaffolds were subcutaneously implanted into C57BL/6 mice for 14 days and showed active angiogenesis within the implantation site while limiting 
the immune response, which is critical for islet survival. Upon recellularization with acinar and beta cells, amylase and C-peptide expression confirmed that these cells localized within their specific physiological niche. Mirmalek-Sani et al. developed a more clinically translatable approach by utilizing porcine pancreata to generate ECM scaffolds, which were seeded with human stem cells and porcine islets [125]. Porcine pancreata were perfused with $1 \%$ Triton X-100 and $0.1 \%$ ammonium hydroxide for $24 \mathrm{~h}$ then rinsed with phosphate buffered saline for 5 more days until tissues were decellularized. Porcine scaffolds seeded with human amniotic fluid-derived stem cells grew significantly after 7 days in culture, confirming cytocompatibility. Additionally, porcine islets that were seeded onto pancreatic ECM demonstrated an increase in metabolic activity and insulin production between 3 and 7 days. Peloso et al., decellularized human pancreatic tissues to move toward the development of a bioartificial endocrine pancreas (BAEP) [126]. The BAEP was generated by decellularizing human pancreata via perfusion of $1 \%$ Triton $\mathrm{X}-100$ and $0.1 \%$ ammonium hydroxide for $48 \mathrm{~h}$ and washing with PBS for an additional 5 days. A chorioallantoic membrane (CAM) angiogenic assay showed that pancreatic ECM triggered neovascularization and did not significantly differ from VEGF, which demonstrates the angiogenic potential of the ECM. Additionally, human pancreatic ECM showed the ability to direct immune cell fate by inhibiting naïve $\mathrm{CD} 4^{+} \mathrm{T}$-cell proliferation, triggering $\mathrm{T}$-cell apoptosis and pushing naïve $\mathrm{CD}^{+} \mathrm{T}$-cells toward T-reg cells. Human islets and endothelial cells cultured on human pancreatic scaffolds initiated insulin secretion and blood vessel formation, which indicates that the human ECM could provide an appropriate niche for generating a functional BAEP. Hashemi et al. tested varying concentrations of detergents and their impact on the decellularization of rat pancreata [127]. Intact vasculature and significant reduction in immunogenic content was optimal using $0.05 \%$ SDS for $6 \mathrm{~h}$ for both cannulation of the common bile duct and aorta. Using the same decellularization protocol, Hashemi et al., showed that acellular rat pancreatic scaffolds were recellularized in vivo post-implantation with de novo vascularization and the presence of infiltrated beta cells [128]. Overall, the development of acellular pancreatic scaffolds has shown great promise for supporting the survival and function of pancreatic islets across species, which could lead to improved outcomes for pancreatic cell transplantation.

In addition to providing a biocompatible pancreas-like niche, next-generation therapies aim to address the shortage of donor islets and immune-rejection. Current strategies are exploring the use of stem cells to mass-produce functional beta cells, which could dramatically reduce or completely replace the need for donor pancreatic tissues. Pagliuca et al. developed a differentiation protocol to generate millions of glucose-responsive human beta cells from human pluripotent stem cells (hPSCs) [129]. This discovery was a major step forward in the effort to replace the need for donor pancreata for islet transplantation; however, these cells are not immune-protected. Therefore, in order to capitalize on this virtually unlimited source of beta cells, it is necessary to develop methods for immuno-protection. Several groups have postulated the use of inert biomaterials that could shield beta cells from immune cells, while allowing for glucose-sensing and insulin secretion. Vegas et al. reported successful application of polymeric encapsulation of human beta cells in diabetic, immune-competent mice [130]. Although encapsulation methods protect beta cells from immune cells and allow normal function, they still face several hurdles, including proximity to blood vessels and foreign body response to biomaterial implantation. However, recent advances in genetic engineering and immunology may lead to the generation of immune-privileged cells without the need for immunosuppression or encapsulation [131,132].

\subsection{Bladder}

Much of the research on bladder whole organ engineering in the past couple decades have been focused on developing decellularized, biomaterial, or composite scaffolds for bladder regeneration in animal models [133-135]. These scaffolds can pose challenges due to the inability to effectively control cellular remodeling of the graft, resulting in incomplete cellular infiltration, fibrotic scarring, and infection of the graft, leading to a loss in function and even death in animal models [136]. This is 
why more recent approaches to bladder tissue engineering have focused on reconstructing the cellular components of the bladder, primarily focusing on the urothelium and smooth muscle layers.

A phase II clinical trial conducted by Joseph et al., used bladder tissue biopsies from children and adolescents with Spina Bifida to create an autologous bladder graft on a biodegradable PLGA scaffold as an alternative to augmentation cystoplasty [137]. Patient-specific grafts were taken from the bladder dome, and then urothelial cells and smooth muscle cells were cultured separately to form layers that were then grafted onto the spherical PLGA scaffold [137]. This construct was then sutured to the inside of the patient's bladder to improve bladder capacity and compliance [137]. This approach failed however due to a lack of bladder cycling after the operation, the limited proliferation capacity of the cells taken from the biopsies in a diseased bladder, and possible expression of the disease phenotype in the grafted cells taken from the diseased bladder [137]. Due to the limitations in proliferative capacity and ease of access of adult bladder cells, pluripotent and adult stem cells have been explored extensively as an alternative for autologous regenerative bladder grafts.

A study conducted by Zhe et al., used bladder acellular matrix grafts seeded with adipose-derived stem cells in a rat model of bladder augmentation [138]. Compared to an unseeded control group, the stem cell-seeded group had greater bladder capacity as well as greater regeneration of smooth muscle and nerve cells [138]. This complete regeneration of tissue in adipose stem cell-seeded BAM's has significant advantages over using autologous cells from bladder biopsies. This is because harvesting adipose tissue from a patient is less invasive than bladder tissue and adipose-derived mesenchymal stem cells (ADMSC) are cheaper and easier to proliferate in culture than terminally differentiated bladder cells. Additionally, ADMSCs are less likely to express a disease phenotype than cells derived from a diseased bladder [138]. Overall, the advantages of using adipose-derived stem cells significantly improves the potential for future clinical translation of Zhe et al.'s technique tested in rats, even compared to other stem cell methods using human embryonic stem cells or bone marrow-derived stem cells due to ethical concerns and the invasiveness of the procedure, respectively [138]. This study has inspired several similar follow-up studies, including one by Moreno-Manzano et al., where human ADMSCs were seeded on a decellularized rat bladder scaffold to regenerate a rat bladder after partial cystectomy [139]. The seeded bladder scaffolds resulted in regeneration of urothelium, smooth muscles, nerves, and even vasculature in the neo bladder to a much greater degree than non-seeded controls, leading the authors to conclude that with further advancements, this technique could be effectively applied to bladder transplantations in humans [139].

\subsection{Skin}

Engineered full-thickness skin grafts should ideally be developed with scaffolding representative of the diverse structure in native epidermis, dermis, and subcutaneous fat, which, similar to other organ engineering methods, has been accomplished using decellularization methods [66]. Using perfusion decellularization of porcine full-thickness skin flaps, Jank et al., created a novel method for generating an acellular skin flap scaffold in 2017 [66]. In vitro tests revealed that the decellularized skin tissue maintained native mechanical properties and could be successfully reendothelialized after perfusion with HUVECs [66]. The most notable results from Jank and colleagues were from their in vivo studies, which found that their engineered skin underwent neovascularization and complete tissue integration at greater rates than native xenogeneic skin or commercially available dermal substitutes when implanted onto full-thickness skin defects [66]. Analysis of the immune cells that migrated to the implant site revealed no evidence of rejection and only showed signs of inflammation associated with the wound healing process, with the acellular scaffold promoting tissue regeneration without signs of scarring [66]. The ability of Jank and colleagues' graft to promote regeneration without scar tissue forming is vital, as scar formation is a significant concern with full-thickness dermal injuries as it can result in severe limitations in function and mobility of an individual.

Other strategies for skin tissue engineering involve the use of de novo ECM bioscaffolds on which cells are seeded so that they can proliferate and generate ECM and tissue [140,141]. 
Sander et al., utilized a biodegradable composite scaffold comprising collagen I and chondroitin-sulfate, a component of cartilage [140]. The scaffolds were seeded with human dermal fibroblasts and then epidermal keratinocytes, evaluating the engineered skin substitute with both in vitro and in vivo studies with athymic mice [140]. The in vitro results demonstrated that mechanical properties of Sander and colleagues' skin substitute were dependent on the combination of materials and cell types used [140]. When comparing the mechanical properties of engineered skin before and after implantation, it was found that implantation was beneficial for the graft to develop more stable mechanical properties that resembled native tissue, as the graft was remodeled by the host [140]. These results were indicative of a viable skin substitute, as the ability of an engineered graft to be remodeled is important for implant integration.

Bottom-up 3D bioprinting approaches have also been utilized in generating full-thickness tissue constructs, particularly to control the placement of structures such as pores and vasculature for the engineered tissue $[142,143]$. Baltazar et al. showed that 3D bioprinting could be used to generate a construct with vasculature, in which several cell types could be cultured [142]. Similarly, Liu et al. used the resolution and control with which bioprinted scaffolds can be generated to create a gelatin scaffold loaded with ECM-components with precise placement of pores [143]. This allowed for the growth of sweat glands within the construct in vitro [143]. The ability to precisely place and grow glandular components of engineered skin is important in skin regeneration, as natural repair mechanisms fail to do so when repairing full-thickness skin injuries.

\subsection{Gastrointestinal}

Similar to bladder whole organ engineering, many of the early approaches to engineering organs of the gastrointestinal tract, including esophagus, stomach, small intestine, colon, and anal sphincter, consisted of a biodegradable polymer, decellularized ECM, or composite scaffold designed to recruit surrounding cells in order to regenerate the host tissue in rat and dog models [144,145]. These approaches have seen successful in small animal models and small defect repair but may not be viable for regenerating larger defects or entire organs as they rely purely on host cells to regenerate the tissue. More recent approaches have also included intestinal organoids cultured in vitro from host cells incorporated into full thickness scaffolds to increase the regenerative potential of these grafts in vivo, which have shown some success in recovering organ function in rat models $[146,147]$. Grafts of this type, however, only exhibited the most basic structural components of functional intestinal tissue and were not evaluated for barrier function as well as digestive and adsorptive capabilities [148]. A more recent study by Grant et al., sought to improve this model by generating intestinal organoids from human and mouse intestinal mesenchymal stem cells and endothelial cells and seeding them onto the surface of biodegradable polyglycolic acid tubes to create a tissue-engineered small intestine (TESI) [148,149]. The TESI constructs were then implanted into transgenic mice and evaluated 4 weeks later ex vivo [148]. The results of this study showed that TESI formed from both human and mouse intestinal stem cells were shown to be highly similar to native tissue in both its ultrastructural components and its secretory, digestive, and absorptive capabilities, indicating a high potential for clinical translation [148]. This technique of using mesenchymal stem cells to regenerate gastrointestinal tissue has been applied to tissue engineering of the stomach in other studies, such as one conducted by Nakatsu et al., which used bone marrow-derived mesenchymal stem cells (MSC) cultured on small intestinal submucosa to patch artificial stomach defects in rats [150]. The presence of mesenchymal stem cells enhanced the regeneration of smooth muscle in the SIS graft compared to an unseeded control, indicating that mesenchymal stem cells have wide applicability in regeneration of hollow organs, especially in the GI tract and bladder [150].

The esophagus is a similar tissue in the GI tract that is a focus of tissue engineering but presents unique challenges as it has a much lower capacity for in vivo regeneration than the intestines and stomach and has to have superior mechanical properties in order to function properly [151]. A recent and highly experimental technique developed by Kim et al., uses a composite polymer scaffold 
composed of an inner layer of electrospun polyurethane nanofibers and an outer layer of 3D-printed polycaprolactone microfibers seeded with human adipose-derived mesenchymal stem cells [151]. The inner electrospun layer enhances cell migration by providing 3D topical cues and the outer layer provides mechanical strength and flexibility to the construct [151]. The seeded constructs were then either cultured in a perfusion bioreactor or transplanted into omental tissue and then used as a full circumferential graft in a rat esophagus [151]. This technique resulted in the regeneration of the mucosa and smooth muscle around the full circumference of the grafted construct, which is not achievable with decellularized constructs alone; however, there were many complications associated with the surgical implantation and mechanical properties of the scaffold, indicating the need for further research on different polymers and natural biomaterials and the need to conduct large animal studies [151]. Despite the significant amount of research needed to bring these whole organ therapies to clinical viability, one GI tract organ therapy that is extremely close to achieving this is tissue-engineered anal sphincters for treating fecal incontinence (FI). A recent study published in Nature Scientific Reports by Dadhich et al. created bioengineered anal sphincters using smooth muscle cells and neural progenitor cells from gut biopsies that were seeded onto a ring-shaped collagen hydrogel [152]. The construct formed an innervated ring of smooth muscle cells that when surgically implanted into a non-human primate FI model, cured the condition within 3 to 4 weeks of the surgery [152].

Table 1. Summary of the most significant publications in the past decade.

\begin{tabular}{|c|c|c|c|}
\hline Year & Title & Number of Citations & Summary and Significance \\
\hline 2010 & $\begin{array}{l}\text { Preparation of Cardiac } \\
\text { Extracellular Matrix from an } \\
\text { Intact Porcine Heart } \\
\text { (Wainwright) [97] }\end{array}$ & 201 & $\begin{array}{l}\text { In this study, a whole porcine decellularized heart } \\
\text { was obtained in less than ten hours using pulsatile } \\
\text { retrograde aortic perfusion of various enzymes, } \\
\text { detergents, and acid solutions. This decellularized } \\
\text { heart not only maintained the ECM components } \\
\text { and mechanical properties of a native heart but also } \\
\text { supported the differentiation of chicken } \\
\text { cardiomyocytes into sarcomeres. This study marked } \\
\text { the first full-scale decellularization of a heart close to } \\
\text { human proportions and paved the way to using } \\
\text { decellularized hearts in preclinical and clinical } \\
\text { studies for cardiac therapies. Additionally, } \\
\text { the perfusion method used for decellularization of } \\
\text { whole organs is superior to previous methods } \\
\text { in maintaining the native ECM compositions } \\
\text { and architecture and efficiently removing cells. As a } \\
\text { result, this method has been adapted for } \\
\text { decellularizing other organ types, advancing } \\
\text { the entire field of whole organ engineering as a result. }\end{array}$ \\
\hline 2011 & $\begin{array}{l}\text { The Use of Whole Organ } \\
\text { Decellularization for } \\
\text { the Generation of a Vascularized } \\
\text { Liver Organoid (Baptista) [63] }\end{array}$ & 393 & $\begin{array}{l}\text { In this study, whole livers were engineered with } \\
\text { functional vasculature by first using perfusion } \\
\text { decellularization of detergents through the vascular } \\
\text { network of the liver followed by perfusion of human } \\
\text { fetal liver and endothelial cells through this vascular } \\
\text { network. This resulted in the creation of whole livers } \\
\text { in vitro seeded with human cells containing } \\
\text { vasculature with fully formed endothelium } \\
\text { and differentiated hepatic and epithelial tissues } \\
\text { surrounding them. This study represents a } \\
\text { significant advancement in whole organ engineering } \\
\text { since many approaches lack the creation of } \\
\text { functional vasculature, which is essential to support } \\
\text { cell viability and tissue function, and struggle to both } \\
\text { adequately decellularize large organs } \\
\text { and recellularize them with the appropriate number } \\
\text { of cells to create a functional engineered organ. } \\
\text { This method overcomes those challenges by using } \\
\text { the existing vascular network of the organ to both } \\
\text { remove the cells, recellularize the organ, and form a } \\
\text { new vascular network to support the organ. } \\
\text { The influence of this study on the field of whole } \\
\text { organ engineering is immense as it opens the door to } \\
\text { clinical translation of engineered whole organs for } \\
\text { organ repair and transplantation. }\end{array}$ \\
\hline
\end{tabular}


Table 1. Cont.

\begin{tabular}{|c|c|c|c|}
\hline Year & Title & Number of Citations & Summary and Significance \\
\hline 2012 & $\begin{array}{l}\text { Decellularization Methods of } \\
\text { Porcine Kidneys for Whole } \\
\text { Organ Engineering using a } \\
\text { High-Throughput System } \\
\text { (Sullivan) [153] }\end{array}$ & 178 & $\begin{array}{l}\text { In this study, whole porcine kidneys were } \\
\text { decellularized with a high-throughput system that } \\
\text { pumped detergents through the renal vasculature. } \\
\text { The porcine cells were successfully cleared while } \\
\text { maintaining the complex microvasculature of } \\
\text { the kidneys as well as the native ECM structure } \\
\text { and composition. The decellularized kidneys were } \\
\text { then evaluated for cytotoxicity and the kidneys } \\
\text { perfused with } 0.5 \% \text { SDS showed no significant } \\
\text { difference in cell viability from tissue plastic controls. } \\
\text { The ability to efficiently and reproducibly } \\
\text { decellularize organs with complex microvasculature } \\
\text { like the kidney at a clinically relevant scale is a huge } \\
\text { step towards clinical translation of engineered whole } \\
\text { organs. Additionally, the low cytotoxicity } \\
\text { and maintenance of ECM composition } \\
\text { and morphology of this method allows for } \\
\text { the application of a number of different } \\
\text { recellularization strategies using pluripotent stem } \\
\text { cells, adult stem cells, and somatic cells. The ability } \\
\text { of this system to simultaneously decellularize } 24 \\
\text { human-sized whole organs at once gives it } \\
\text { the production efficiency to meet the high unmet } \\
\text { demand for whole organ transplantation. Overall, } \\
\text { this study marks the first step towards mass } \\
\text { production of clinically relevant ECM scaffolds for } \\
\text { whole organ engineering. }\end{array}$ \\
\hline
\end{tabular}

In this study, the unmet need for a regenerative medicine therapy to address type I diabetes is addressed by creating a decellularized pancreas whole organ and reseeding it with pancreatic cells. The pancreas was perfused with $0.5 \%$ SDS through the pancreatic vasculature to remove the cellular components. These scaffolds were successfully implanted in vivo without killing surrounding cells or inducing the foreign body response. The scaffolds were also seeded in vitro with beta islet and acinar cells using retrograde perfusion of the hepatic portal

Perfusion-Decellularized Pancreas as a Natural 3D 2013 Scaffold for Pancreatic Tissue and Whole Organ Engineering (Goh) [124]

types maintained high viability and showed appropriate localization in the scaffold during a five-day culture period. Additionally, the beta cells maintained insulin production capabilities and the acinar cells maintained amylase production over the entire culture period. This study is the first successful attempt at creating a tissue-engineered whole pancreas that produces insulin and provides a unique opportunity for the millions of people afflicted with type 1 diabetes. This treatment could eventually replace insulin injections and pumps, which are expensive and inconvenient, as a treatment for type 1 diabetes by instead providing an engineered whole organ transplant that would function as an autologous native pancreas.

Though leveraging the native ECM structure and biochemistry of cadaveric whole organs via decellularization and recellularization is a promising approach to engineering whole organs, one of its limitations is the time needed to perfuse and decellularize the organs. In this publication, Bonandrini et al. presented an accelerated perfusion decellularization protocol that was capable of using an ionic detergent solution of SDS to decellularize rat kidneys in just $17 \mathrm{~h}$, with sufficient preservation of

Recellularization of

2014 Well-Preserved Acellular Kidney Cells (Bonandrini) [154] native ECM for infused murine embryonic stem cells to uniformly distribute, attach, and begin to differentiate. This relatively short time to decellularize rat kidneys is significant due to the need for improved manufacturing efficiencies for engineered whole organs to be clinically relevant. However, this protocol is limited due to a lack of replication in human-scale organs and its specificity to kidneys. Different tissues require varying decellularization protocols, and only using an SDS as the decellularization solution may not translate to other organs due to the documented harshness of ionic detergents. 
Table 1. Cont.

\begin{tabular}{lll}
\hline Year & Title & Number of Citation
\end{tabular}

Whole-Organ Tissue

Engineering: Decellularization

2015

Three-Dimensional Matrix Liver

Scaffolds (Sabetkish) [155] and Recellularization of

Summary and Significance

In this study, rat and sheep livers were decellularized through perfusion of either Triton X-100 + SDS or

SDS-only detergents and then recellularized either by in vivo implantation into rats or in vitro through perfusion of cell suspension media through the hepatic vein of the decellularized constructs.

The results of the study showed that

decellularization using the Triton X-100 + SDS

detergent showed superior removal of cells, maintenance of native ECM architecture,

and retention of mechanical properties relative to native tissue. These decellularized whole organs were successfully reseeded with hepatocytes in vivo and in vitro. The in vitro reseeding resulted in a native liver-like cellular architecture infiltrating both the regions surrounding the vessels

and the parenchyma. This study represents a significant advancement over previous de-cell-re-cell studies of whole livers, which were only able to recellularize the vasculature or areas immediately surrounding the vasculature, whereas this study developed a technique for decellularization that enabled cellular infiltration throughout the entire thickness of the construct. This is a major step towards clinical viability of engineered whole organs since many rely on perfusion recellularization approaches but have had limited success with seeding the entire organ due to the distorted morphology of the ECM resulting from using an SDS only method of decellularization.

In this study, human hearts were decellularized using perfusion-decellularization to obtain human acellular cardiac scaffolds and whole heart scaffolds. Scaffolds derived from 2D and 3D slices of acellular human myocardium were seeded with iPSC derived cardiomyocytes in static culture conditions and formed contractile cardiac tissue after 4-7 and 7-10 days, respectively. Human whole heart scaffolds were partially seeded with iPSC-derived cardiomyocytes by injection into different regions of the left ventricle followed by coronary artery perfusion of media and left ventricle wall mechanical stimulation in a custom bioreactor. The resulting ventricle tissue showed 50\% cellular repopulation and maintained $90 \%$ cell viability over the culture period. The tissue also demonstrated visible

Bioengineering Human

(Guyette) [98]

contractile function when electrically stimulated and produced measurable spontaneous contractions and ventricular pressures of $2.4 \mathrm{mmHg}$. While this study did not produce a fully functional engineered heart, it is the closest anyone has come to producing an engineered whole heart at the clinically relevant scale. Additionally, this study used iPSCs to recellularize the whole heart matrix, which can allow for the creation of a patient-specific organ by obtaining iPSCs from the transplant patients own tissues. The ability to create a patient-specific organ for an organ with such complexity and high metabolic demands as the heart makes this study is a major milestone in the field of whole organ engineering. More work is needed to develop this technique to produce engineered whole human hearts that are clinically relevant for transplantation. 
Table 1. Cont.

\begin{tabular}{|c|c|c|c|}
\hline Year & Title & Number of Citations & Summary and Significance \\
\hline 2017 & $\begin{array}{l}\text { Bioengineering of Functional } \\
\text { Human Induced Pluripotent } \\
\text { Stem Cell-Derived Intestinal } \\
\text { Grafts (Kitano) [156] }\end{array}$ & 39 & $\begin{array}{l}\text { In 2017, Kitano and colleagues published their } \\
\text { research on the successful engineering of intestinal } \\
\text { grafts populated with human iPSCs, which, after } 28 \\
\text { days of culturing, demonstrated intestine-specific } \\
\text { functionality. Sections of intestine were perfusion } \\
\text { decellularized and then recellularized using } \\
\text { spheroids comprising human iPSCs, with these } \\
\text { spheroids adhering to the scaffold and forming a } \\
\text { functional epithelial barrier capable of transferring } \\
\text { nutrients across itself. These functional intestine } \\
\text { grafts were then implanted into mice, after which } \\
\text { the epithelial layer formed further matured } \\
\text { and continued to transfer glucose and fatty acid } \\
\text { nutrients. The functionalization of an implanted } \\
\text { engineered graft is highly promising; however, } \\
\text { this protocol is suited towards relatively simpler } \\
\text { organs comprised of thinner tissues and may not be } \\
\text { able to be translated for engineering more complex } \\
\text { whole organs with thicker, more solid tissue } \\
\text { compositions. }\end{array}$ \\
\hline
\end{tabular}

In this study, human-scale tissue-engineered lungs were created by perfusion decellularization of porcine whole lungs with SDS followed by Triton $X-100$. The vasculature of the lungs was then seeded with HUVECs by perfusion of cell suspension media through the pulmonary artery and vein. Epithelial cells were seeded into the bronchi in media suspension at a pressure of $80 \mathrm{mmHg}$ followed by a period of perfusion culture through the pulmonary artery for 6 days to allow for endothelialization and epithelialization of the decellularized lung scaffold. The engineered lungs were then transplanted into adult pigs and evaluated for Bioengineering Human Lung

gas exchange and perfusion in vivo.

The tissue-engineered lungs not only developed endothelialized vasculature and capillaries as well as a complete epithelium in the bronchial tubes, but the endothelial and epithelial cells rebuilt functional alveoli in the decellularized ECM allowing for gas exchange to occur. While the capacity for gas exchange of the engineered lungs was about $50 \%$ of that of the native lung in the porcine model, this study is the first to successfully create a whole bioartificial lung at a clinically relevant scale that recapitulates the function of the native lung in vivo. With further research, this technique could potentially produce clinically relevant bioartificial lungs for human transplant.

Leuning et al., demonstrated that focusing on preservation of GAGs when decellularizing kidneys can result in improved reendothelialization after infusing the kidneys with cells. They found that GAG preservation resulted in enhanced reendothelialization when coupled with preloading of growth factors, as the growth factors utilize GAGs to exert their effects. In addition, they developed a novel perfusion recellularization system that

Vascular Bioengineering of Scaffolds Derived from Human Discarded Transplant Kidneys using Human Pluripotent Stem Cell-Derived Endothelium (Leuning) [157] improved endothelial covering of the vasculature by the infused endothelial cells derived from iPSCs. The methods presented in this publication were successfully used on both mouse and human cadaveric kidneys. As adequate endothelialization is vital for vasculature to function properly in organs, Leuning and colleagues' work is a notable contribution to whole organ engineering. Their work in retaining specific ECM components during decellularization and developing a novel recellularization method, if translatable to other organs, would be a very useful protocol. 
Table 1. Cont.

\begin{tabular}{|c|c|c|c|}
\hline Year & Title & Number of Citations & Summary and Significance \\
\hline 2020 & $\begin{array}{l}\text { Fast, Robust and Effective } \\
\text { Decellularization of Whole } \\
\text { Human Livers using Mild } \\
\text { Detergents and Pressure } \\
\text { Controlled Perfusion } \\
\text { (Willemse) [158] }\end{array}$ & 4 & $\begin{array}{l}\text { This study developed an improved technique for } \\
\text { perfusion decellularization that keeps a constant } \\
\text { pressure of } 120 \text { mmHg in the perfused detergent } \\
\text { solution and uses only TX-100 instead of SDS or a } \\
\text { combination of SDS and TX-100. The researchers first } \\
\text { conducted a preliminary study with porcine livers to } \\
\text { show the decellularization properties of different } \\
\text { detergent combinations when perfused through } \\
\text { the liver vasculature. The preliminary study showed } \\
\text { that while SDS is more effective at clearing cells from } \\
\text { the tissue, it is a harsh solvent and partially destroys } \\
\text { the ECM and GAGs of the livers in the process, } \\
\text { which makes it less effective as a biomimetic scaffold. } \\
\text { In contrast, the TX-100 does not damage the ECM } \\
\text { and GAGs but does not remove cells efficiently } \\
\text { enough in oscillating flow conditions. } \\
\text { The pressure-controlled TX-100-only method } \\
\text { overcame both of the issues with the previous } \\
\text { methods. The constant pressure enabled the TX-100 } \\
\text { to more efficiently clear cells from the tissue, cutting } \\
\text { down the decellularization time to } 20 \text { h compared to } \\
96 \text { for the oscillating flow TX-100 protocol, } \\
\text { and the use of TX-100-only preserved the ECM } \\
\text { and GAGs of the liver tissue. To prove } \\
\text { the effectiveness of this procedure, the human liver } \\
\text { tissue and whole porcine livers were perfusion } \\
\text { recellularized with hepatic cells and the resulting } \\
\text { engineered tissues/organs showed high cell viability } \\
\text { and significant cellular infiltration of the parenchyma. } \\
\text { This improved method for decellularization of whole } \\
\text { organs will improve the quality and resulting clinical } \\
\text { viability of future tissue-engineered whole organs } \\
\text { that utilize this method, not just liver. }\end{array}$ \\
\hline
\end{tabular}

\section{Supporting Technological Advances}

\subsection{Cell Transplantation}

Cell transplantation therapies for organ function restoration and tissue regeneration have been developed utilizing adult cells, adult stem cells, and iPSCs [159-162]. Similar to organ transplantation, adult cell transplantation has been used to substitute for a lack of native organ function. The insulin-producing beta islet cells of the pancreas have been transplanted into patients with type I diabetes and have been successful in maintaining blood sugar levels by releasing insulin into the host after implantation $[159,163]$. The case of islet transplantation is unique in that islet cells make up only about $2 \%$ of the pancreas but transplanted islets are still able to provide clinically relevant levels of insulin without pancreatic tissue being transplanted as well [159]. Recognizing what part or parts of an organ are most vital to its function, such as the islet cells for the pancreas, are critical for engineering functional whole organs. Adult stem cells and iPSCs have both been used to regenerate cells and damaged tissue via injection $[160,161]$. Stem cells are transplanted with the intention of using the microenvironmental cues of the surrounding tissue to induce differentiation of the stem cells into the same type of cell as the tissue they are injected in [164]. For instance, myoblasts have been injected into a site of myocardial infarction in several animal models, with transplantation being shown to improve the heart structure, tissue mechanics, and overall functioning [160]. The promising results of stem cell transplantation for tissue regeneration provide valuable insight into the role that the microenvironment of native ECM can have on cell functions and can be translated into growing cells for whole organ engineering.

\subsection{Immuno-Therapy}

Modulating the immune response has been a core part of tissue transplantation. The inflammatory response in particular is an issue for implanted materials, as inflammation can lead to biomaterial encapsulation in fibrin [165]. In addition, host immune response becomes an even greater concern once 
cells are implemented in a bioscaffold, as non-autologous cells will present antigens to the host immune system that will elicit an immune response [9]. Understanding how the immune system responds to foreign materials and cells through the study of therapies to modulate the immune system has led to the development of various materials that can mitigate the immune response that can be applied to bioscaffolds and organ engineering [166]. Furthermore, immunotherapies have been developed that engineer biomaterials to influence the adaptive immune system's cells, namely the B and T cell lymphocytes [166]. T lymphocytes typically differentiate into cytotoxic $\mathrm{T}$ cells to kill cells infected with pathogens and B lymphocytes differentiate into antibody secreting cells. Both lymphocyte types play a role in modulating macrophage phenotype and the implant/injury response pathways through which new ECM materials are synthesized [166]. Biomaterials have been developed such that their interactions with lymphocytes and macrophages promote a regenerative phenotype instead of a foreign body response [166]. Leveraging this kind of immunomodulation in engineering bioscaffolds could be highly conducive towards the integration of cells and tissue grown on the scaffold as well as integration of the construct upon implantation.

\subsection{Three-Dimensional Cell Cultures}

Three-dimensional (3D) cell cultures are one of the key technologies that form the basis of whole organ engineering. Cell morphology can greatly affect the cell's functions, and 2D cultures can alter a cell's morphology from its native shape by a great extent. Cells extracted from tissue and placed in a 2D culture become flat, can fail to divide, and lose their differentiated phenotype [167]. Cells that have lost their native morphology and function after transfer to a 2D culture have been shown to regain their native phenotype after placement in a 3D culture gel, further emphasizing the importance of a dimensionally biomimetic cell scaffold [168]. This is because when compared to 2D cell cultures, $3 \mathrm{D}$ culture environments are more similar to in vivo environments for most tissues and are thus able to produce more physiologically similar cell activity for most cell types [169]. One of the seminal works in developing 3D cell culture environments and in demonstrating the merit of using ECM molecules as the scaffold material of choice was work by Mina Bissell examining the effect of 3D gel substrates on gene expression of cultured cells [170]. Her work, along with most early 3D cell culture methods, utilized hydrogels with more basic compositions, such as collagen gels. However, as 3D cell culture scaffolds were further developed, more structurally and compositionally advanced scaffolds were generated, such as engineering scaffolds to have built-in porosity to assist in cell infiltration and adhesion [11]. Three-dimensional cell cultures showed great promise in being able to better replicate in vivo functions than $2 \mathrm{D}$ cultures, allowing for more accurate in vitro cell biology studies and disease modelling, with this ability leading to 3D cell culture use in tissue engineering [11].

\subsection{Stem Cell Technologies}

Human pluripotent stem cells, whether created via derivation from an embryo or through induced pluripotency, are capable of indefinite self-renewal and possess the ability to differentiate into essentially all mature cell types, and as a result are highly attractive candidate cell sources for engineering tissue [171,172]. Human embryonic stem cells (hESCs) are derived from the inner cell mass of an embryo and have the intrinsic potential to differentiate into any type of cell because hESCs are the progenitors of every cell in the human body. hESCs have been successfully differentiated in vitro to become neural, cardiac, and pancreatic islet cells, among many others [171]. In addition to their differentiation potential, hESCs are favorable for tissue engineering and particularly for whole organ engineering because they can be cultured and expanded while in an undifferentiated, pluripotent state for an indefinite period of time, and as such could be expanded to produce a quantity of cells on the scale needed to seed organ sized tissue scaffolds before being differentiated into the functional cells needed [173]. However, even though they can be expanded in culture while undifferentiated, hESCs being derived from human embryos means the source is not very abundant and produces additional ethical considerations. Also, since hESCs cannot be sourced autologously, any potential use 
involving implantation of hESCs would require genetic modification to avoid an immune response. iPSCs are another form of hPSCs that address some of the drawbacks of hESCs, as iPSCs are sourced autologously. When delivering certain transcription factors to human adult cells placed in hESC culture conditions, the adult cells revert to a pluripotent state [174]. iPSCs are valuable in whole organ engineering because they offer a patient-specific cell source that, depending on the cell type, can also be abundantly sourced [175].

A patient-specific alternative to human pluripotent stem cells for whole organ engineering is adult stem cells. These are partially differentiated stem cells, such as mesenchymal or hematopoietic stem cells, derived from mature tissues that can differentiate into multiple different cell types and can be used to reconstruct organs from patient biopsies. Human adipose-derived mesenchymal stem cells were used to reconstruct bladders on decellularized ECM scaffolds in rat models to regenerate smooth muscle and nerve [139], and they were also used in a biohybrid esophagus implanted in rats to generate smooth muscle in a polycaprolactone and polyurethane tubular scaffold [151]. Adipose-derived mesenchymal stem cells (ADMSC) provide a unique advantage because they are abundant in host tissues, they can be harvested non-invasively, and they can be easily proliferated in culture to therapeutically appropriate levels [176]. ADMSCs have also been shown in some studies to have an immunoregulatory effect on surrounding tissues, preventing immuno-rejection of tissue grafts upon implantation in the host tissue [177]. Most importantly, ADMSCs can be differentiated into a number of different cell lineages, including muscle, endothelial, bone, cartilage, fat, and even neural tissue efficiently and reproducibly [178-180]. This makes ADMSCs suitable for engineering whole organs comprising these cells, as ADMSCs can be easily sourced and proliferated into a population large enough to seed an organ-sized construct and are patient-specific.

An important consideration in developing engineered organs that incorporate stem cells or stem cell-derived cells is the tumorigenicity of pluripotent stem cells [178,181-184]. Both hESCs and iPSCs have been observed to form tumors comprising tissue from all three germ layers, called teratomas. This has most notably been demonstrated in stem cell therapies involving direct injection of pluripotent stem cells into patient tissues, and iPSCs have been shown to be more tumorigenic than hESCs in vitro; however, research has also shown iPSC-derived cells to be tumorigenic as well [181-186]. Different whole organ engineering approaches that utilize perfusion recellularization of an acellular scaffold have been developed constituting a variety of techniques and cells of different potency, ranging from iPSCs and progenitor cells to terminally differentiated cells. Due to the risk of tumor formation, it is vital that these inconsistent recellularization protocols be standardized for each organ type to eliminate the risk of tumor formation in whole organs engineered using stem cells and their derivatives. As such, further development of stem cell technologies, particularly those that aim to improve the efficiency and safety of pluripotent stem cell differentiation, is a key component of advancing whole organ engineering.

\subsection{Genetic Engineering}

CRISPR-Cas-based technologies have gained prevalent use in genetic modification research as a result of their accessible and versatile ability to alter, regulate, and visualize genomes, enabling significant advancement in the field of whole organ engineering. CRISPR-Cas tools have been successfully utilized to accelerate genetics-focused research development, being suitable tools for improving understanding of the genetics of diseases and new organisms. Cas-based biotechnology is developing rapidly, to the extent that there are several clinical trials, both in progress or beginning soon, that depend on Cas9 technology, and the results of which will likely determine how somatic cell editing is used both in research and clinical applications in patients.

Human pluripotent stem cells such as iPSCs have strong potential in regenerative medicine applications. Despite this potential, applications are limited by the risk of immune rejection arising from an HLA mismatch. Cas9 techniques such as B2M gene knockout or HLA-homozygous iPSC stocks have the potential to address immuno-compatibility concerns, however B2M knockout runs the risk of eliciting natural killer (NK) cell activity and failing to present antigens, and for HLA-homozygous iPSC 
stocks, it can be difficult to recruit the rare donors needed. $\mathrm{Xu}$ and colleagues have developed two approaches for gene editing of iPSCs to make them immuno-compatible [187]. The first is a method of generating HLA pseudo-homozygous iPSCs by using allele-specific editing to genetically modify HLA heterozygous iPSCs. The second method involves disrupting both HLA-A and HLA-B alleles as a means of suppressing the NK cell response while still retaining antigen-presenting capabilities, producing HLA-C retaining iPSCs as a result. This is valuable because iPSCs that retain HLA-C have been shown to evade T cells and NK cells, both in vitro and in vivo. It is estimated that at least $90 \%$ of the human population could be compatible with cells produced by combining 12 lines of HLA-C-retained iPSCs with HLA-class II, which greatly facilitates iPSC-based regenerative medicine applications.

\section{Major Challenges and Barriers to Market}

\subsection{Incorporation into Host Tissue}

Vascular regeneration and innervation potential are essential for fully functioning transplants, and are the most important among the technical challenges outlined in Figure 4 for achieving integration into host tissue. An ongoing obstacle in establishing angiogenesis within engineered tissue constructs is developing a way to provide sufficient vascularization for tissues with volumes greater than $2-3 \mathrm{~mm}^{3}$. Without such vascularization built-in to tissue constructs, necrosis will occur before ingrowth of host blood vessels can occur. Although some organs and tissues can successfully be manufactured and transplanted without engineered vasculature, as shown by Elliot et al. in 2012 when they were able to transplant bioengineered tracheas [188], it is clear that a functional vascular network is a prerequisite for generating more complex organs.

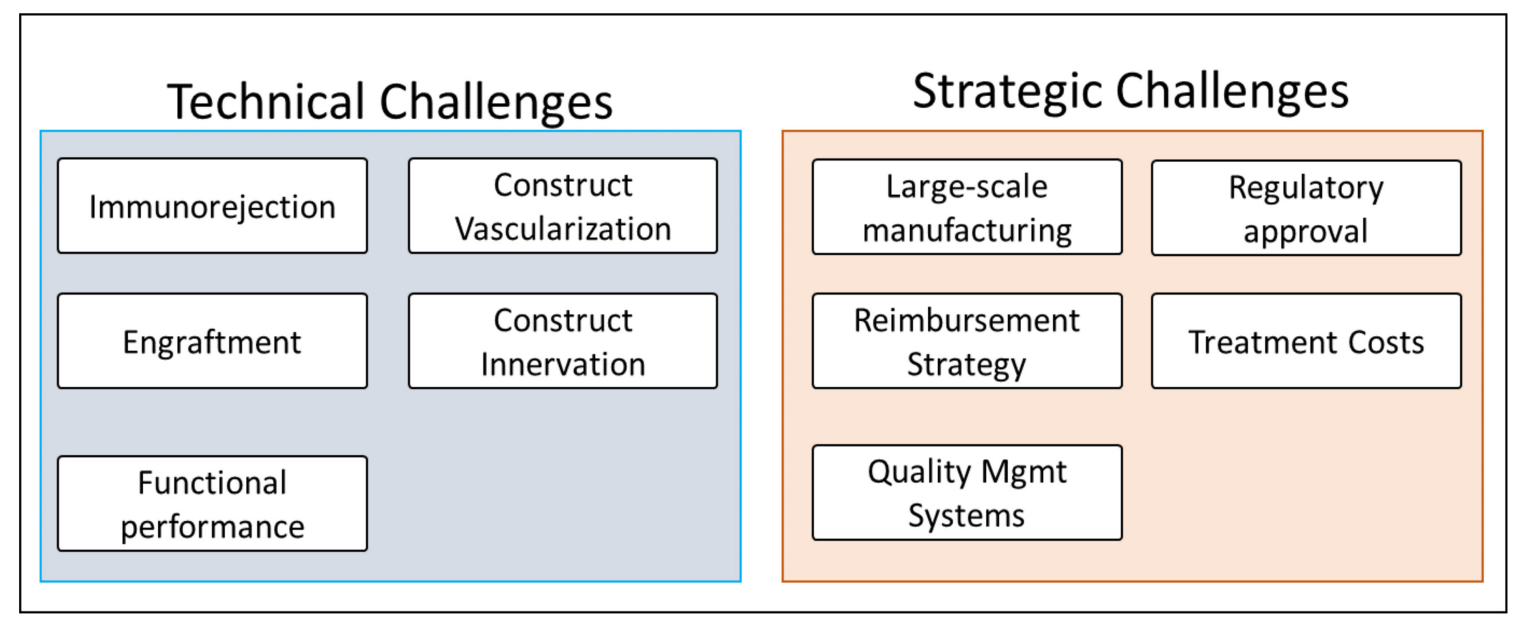

Figure 4. Major challenges to clinical implementation and commercialization of engineered whole organs.

A newer branch of angiogenic tissue engineering incorporates the formation of the lymphatic system in bioengineered tissues and organs. As is the case with angiogenesis, lymphatogenesis in engineered whole organs requires the control of tissue growth and the prevention of metastatic behavior $[189,190]$. Incorporation of a construct into host tissue also requires innervation, and while controlled axonal growth has been demonstrated in tissue engineering research [191], methods for controlling the innervation of tissue constructs must be improved. While autologous peripheral nerve grafts derived from the epineurium or sural nerve are the conventional treatment standards for regenerating peripheral nerve injuries, autografts are limited by: limit of supply, the possibility of creating wound pain, and the risk of causing lasting motor function reduction [192,193]. Innervating an organ requires matching the mechanical properties of the graft with that of the surrounding tissue of the implant site to facilitate diffusion and produce the appropriate degradation profile for when nerve regeneration begins and axon recruitment from nearby nerves occurs $[191,193]$. 


\subsection{Achieving Sufficient Organ Function Post-Implantation}

Sufficient parenchymal cells are required to integrate and repair new organs. In porous scaffolds, it can be difficult to generate a homogeneous cell distribution, and often times cells that are seeded onto a scaffold will remain on the outlying surface of the construct, resulting in a thin peripheral layer of cells forming instead of a homogeneous infiltration of cells. In addition, controlled distribution of incorporated cells cannot be achieved when dealing with multiple cell types. This severely limits the creation of larger scale organs in more complex systems such as liver, lung, and kidney [194]. Additionally, in decellularized organ scaffolds, cell infiltration is even harder to achieve due to an insufficient number of pores in the scaffolds. Decellularized scaffolds have lower potential for cell infiltration as organs proceed towards adult stages of development [195].

\subsection{Cost of Large-Scale Manufacturing}

Adequately recellularizing organ-sized constructs such as the liver or heart with enough cells to replicate native organ functionality will require billions of cells [196,197]. For instance, clinically relevant contractile function in an engineered whole heart would require a quantity of cells on the scale of the 2-3 billion cardiac muscle cells found in the native heart, and even then that is less than a third of the number of total cells in the heart [197]. In addition to the cost of the cell and relevant culturing equipment, large-scale manufacturing of tissue using conventional tissue engineering techniques would require a large number of personnel that would need to be trained in cell culture techniques, requiring time and money. An approach that may be able to improve upon conventional tissue culture methods and expand them to large-scale manufacturing is the use of advanced robotics in manufacturing. Not only could robotic manufacturing produce a larger scale of cells without the need for training personnel, but fabrication could be performed in a closed system, reducing the risk of contamination and thus further saving costs by mitigating the need to discard contaminated cells. In addition, using machine learning algorithms and imaging techniques, manufacturing robots could be trained to identify cells in a culture that have successfully undergone genetic modification or differentiation and then isolate them for expansion, improving the efficiency of stem cell-derived cells for tissue engineering. However, implementing novel manufacturing approaches in engineered tissues would require extensive regulations for developing protocols and investigating the safety of the process.

A majority of the published preclinical research studies involving decellularization and recellularization have been unable to establish the cell numbers needed to restore original organ function. Uygun et al., were able to recellularize a liver with roughly 5-20\% of the original native hepatic mass in their preclinical animal model [40]. Park et al. were able to repopulate a decellularized rat liver with roughly 20 million iPSCs, which were able to differentiate into hepatic cells [198]. However, this only corresponds to less than $5 \%$ of the whole rat hepatocyte cell count. The cost of these studies were thousands of dollars. In order to make whole organ engineering, these numbers would have to be scaled to orders of magnitude higher, which would be extremely expensive. In order to decrease contamination and improve functionality, more money would have to be spent on improving quality control metrics.

\subsection{Regulatory Approval}

A unique challenge confronting the development of engineered tissues and organs not encountered in the use of donor organs is the administrative policies that must be satisfied. In the US, the Health Resources Service Administration regulates the National Organ Transplant Program. However, engineered whole organs fall under the category of HCT/Ps (human cells, tissue, and cellular and tissue-based products), and are regulated by the FDA via the Center for Biologics Evaluation and Research (CBER) and under Title 21 of the Code of Federal Regulations (CFR) [199]. Parts 1270 and 1271 of Title 21 specifically outline the rules and practices that must be adhered to when implanting or infusing HCT/Ps, including policies for screening and testing the tissue sources [200]. 
Furthermore, because of the novel and untried nature of engineered whole organs in humans, any engineered organ developed would be subject to Premarket Approval (PMA) regulations according to part 814 of Title 21 before being eligible for establishment as a medical product [199,200]. Parts 1270 and 1271 of Title 21 specifically outline the rules and practices that must be adhered to when implanting or infusing HCT/Ps, including policies for screening and testing the tissue sources [200].

An engineered whole organ would be considered a Class III device under PMA guidelines, which is the most stringently regulated device type. This is understandable as Class III devices are those that will be used to sustain human life or prevent substantial impairment of health and are devices with the highest risks associated with their use $[199,201]$.

A PMA application must demonstrate safety and effectiveness of the proposed device via non-clinical laboratory testing in compliance with part 58 of CFR Title 21, with these non-clinical studies demonstrating enough merit for the device to safely advance to clinical investigations to show safety and effectiveness in humans, which must also be included in the PMA application. It is crucial to maintain ethical protocols and patient safety when beginning clinical studies for a Class III PMA. Though there are study protocols that can be adapted from previous clinical studies using allogenic transplants and synthetic implants, the novel and high-risk nature of implanting engineered whole organs means that new, stringent approaches for assessing the safety of engineered whole organs in preclinical and clinical studies will need to be developed.

Further administrative challenges will need to be dealt with for any whole organ device that receives PMA. A novel device such as an engineered whole organ will likely be unviable in the medical device market if insurance companies do not reimburse costs for implementing it. Because of this, a new medical device will benefit from being developed to benefit not only patients but also insurance companies, i.e., be cost effective. As such, preclinical and clinical tests of an engineered whole organ should be done to demonstrate the device's safety, efficacy, and capacity to perform without costly downsides of current methods of treating end-stage organ disease. For engineered whole organs, this condition could potentially be achieved largely due to the fact that the organs will use patient-specific cells, eliminating insurance costs associated with allogenic transplants (e.g., medication for patients on a transplant waitlist, medication after transplant surgery to mitigate transplant rejection, and potential subsequent surgery if transplant rejection does occur). However, while engineered whole organs have some potential advantages over allogenic organ transplants in terms of economic costs, there is also a potential downside. Namely, the process of engineering whole organs is expensive, as specific cell culture and tissue engineering materials, methods, and training are needed in most, if not all, whole organ engineering approaches.

Additionally, while patient specificity is one of the main attractive features of whole organ engineering, it also further increases the economic cost of engineering a whole organ, as traditional manufacturing methods are not suited for adaptation to large-scale, low-cost manufacturing of custom organs. A potential solution to this problem lies in the field of advanced robotics, wherein complex and precise machines can perform tissue engineering procedures autonomously via machine learning algorithms, potentially increasing both the scale and efficiency of whole organ engineering. Of course, regulatory concerns must be considered in order to implement such novel manufacturing technology.

\section{Conclusions}

There has been significant interest in the fields of whole organ engineering, tissue engineering, and regenerative medicine over the past few decades. This has been especially true because of the fact that end-stage organ failure continues to be a leading cause of morbidity and mortality around the world. Orthotopic organ transplantation is currently the only curative treatment option available for patients diagnosed with end-stage organ failure. However, significant advances in bioengineering of whole organ constructions continue to advance at a rapid pace, giving hope to those awaiting transplantation.

Whole organ engineering has been supported by key technological advancements over the past few decades. These include (1) methods of whole organ decellularization and recellularization, 
(2) three-dimensional bioprinting, (3) advanced stem cell technologies, and (4) the ability to genetically modify tissues and cells. These advancements give hope that organ engineering will become a commercial reality in the next decade. However, several barriers to commercialization are still major obstacles that need to be systematically addressed. Engineering whole organ constructs with adequate cell populations is a significant technical barrier, as it is currently highly challenging to create an engineered organ with a homogenous cell density close to the high cell density that native organs possess. To address this barrier, stem cell research must be developed to improve cell invasion and adhesion of organ constructs. In addition to improving density of cells incorporated into engineered whole organs, the diversity of cells used must also be improved to better mimic the cell diversity found in native organ tissue. Though whole organ de-cell/re-cell approaches and cell bioprinting approaches have demonstrated the ability to incorporate multiple cell types into engineered organ constructs, this is often for the purpose of replicating but a single part of an organ's function, rather than replicating the entirety of the organ's functions. Also, though the variety of approaches to stem cell culture and differentiation, whole organ recellularization and decellularization, bioprinting, and genetic modification techniques being developed is conducive for research purposes, standardization is vital for clinical implementation of these techniques. Standardization necessitates the comparison of various methods in comprehensive studies for identifying the safest and most effective approaches to engineering whole organs, as demonstrated by multiple studies performed by different research groups. As the ultimate goal of whole organ engineering is clinical translation and transplantation, these standardized protocols would have to undergo strict regulatory examination.

Regulatory pathways are an additional challenge facing the utilization of engineered whole organs as viable transplants and are principal among the non-technical barriers to commercial implementation. This is an important challenge, as regulatory pathways ensure that novel medical technologies can only be used commercially if they can properly demonstrate safety, with all potential risks and their respective likelihood of occurring being documented. An additional challenge outside of developing transplantable whole organ technology is the manufacturing of said organ. Current approaches for engineering whole organs are very involved processes with low production volumes and no indication of the ability to maintain consistent quality on a commercial scale. As a result, current methods of whole organ engineering would not be able to make a difference in reducing the number of individuals that die from end-stage organ failure. As such, it is necessary to develop novel manufacturing techniques in parallel with ongoing whole organ engineering research.

Despite the field of whole organ engineering being quite new, much attention in research has been focused on it and relevant technologies, such as stem cells developed with the goal of advancing whole organ engineering. Though there are many barriers to the clinical implementation of engineered organs, the critical need for a replacement for allogeneic organ transplantation makes whole organ engineering research vital in overcoming these barriers.

Author Contributions: Writing-Original draft preparation, S.S., M.V.B., M.J.B., R.L. and D.F.; writing-Review and editing, S.S., M.V.B., M.J.B., R.L. and D.F.; writing-Figures, S.S. and R.L. All authors have read and agreed to the published version of the manuscript.

Funding: This research received no external funding.

Conflicts of Interest: The authors declare no conflict of interest.

\section{References}

1. Centers for Disease Control and Prevention. Heart Failure / cdc.gov. 2019. Available online: https: //www.cdc.gov/heartdisease/heart_failure.htm (accessed on 23 April 2020).

2. Chronic Kidney Disease in the United States. 2019. Available online: https://www.cdc.gov/kidneydisease/ publications-resources/2019-national-facts.html (accessed on 23 April 2020).

3. Kidney Disease Statistics for the United States | NIDDK. Available online: https://www.niddk.nih.gov/healthinformation/health-statistics/kidney-disease (accessed on 23 April 2020). 
4. Grinyó, J.M. Why is organ transplantation clinically important? Cold Spring Harb. Perspect. Med. 2013, 3, a014985. [CrossRef] [PubMed]

5. U.S. Department of Health \& Human Service. Organ Donation Statistics | Organ Donor. Available online: https://www.organdonor.gov/statistics-stories/statistics.html (accessed on 20 April 2020).

6. Global Observatory on Donation and Transplantation (GODT). International Report on Organ Donation and Transplantation Activities_-2017, no. October; World Health Organization: Geneva, Switzerland, 2019; pp. 1-52.

7. Matching Donors and Recipients | Organ Donor. Available online: https://www.organdonor.gov/about/ process/matching.html (accessed on 23 April 2020).

8. Ingulli, E. Mechanism of cellular rejection in transplantation. Pediatr. Nephrol. 2010, 25, 61-74. [CrossRef] [PubMed]

9. Duncan, M.D.; Wilkes, D.S. Transplant-related Immunosuppression A Review of Immunosuppression and Pulmonary Infections. Proc. Am. Thorac. Soc. 2005, 2, 449-455. [CrossRef] [PubMed]

10. Langer, R.; Vacanti, J. Tissue engineering. Science 1993, 260, 920-926. [CrossRef] [PubMed]

11. Vacanti, J.P.; Morse, M.A.; Saltzman, W.M.; Domb, A.J.; Perez-Atayde, A.; Langer, R. Selective cell transplantation using bioabsorbable artificial polymers as matrices. J. Pediatr. Surg. 1988, 23, 3-9. [CrossRef]

12. Vacanti, J.P. Beyond Transplantation. Arch. Surg. 1988, 123, 545. [CrossRef]

13. Lee, E.J.; Kasper, F.K.; Mikos, A.G. Biomaterials for tissue engineering. In Annals of Biomedical Engineering; Kluwer Academic Publishers: Berlin/Heidelberg, Germany, 2014; Volume 42, pp. 323-337.

14. Dhandayuthapani, B.; Yoshida, Y.; Maekawa, T.; Kumar, D.S. Polymeric scaffolds in tissue engineering application: A review. Int. J. Polym. Sci. 2011, 2011, 290602. [CrossRef]

15. Lanza, R.; Langer, R.; Vacanti, J. Principles of Tissue Engineering, 2nd ed.; Academic Press: Cambridge, MA, USA, 2000.

16. ter Horst, B.; Chouhan, G.; Moiemen, N.S.; Grover, L.M. Advances in keratinocyte delivery in burn wound care. Adv. Drug Deliv. Rev. 2018, 123, 18-32. [CrossRef]

17. Chen, F.M.; Liu, X. Advancing biomaterials of human origin for tissue engineering. Prog. Polym. Sci. 2016, 53, 86-168. [CrossRef]

18. Dolcimascolo, A.; Calabrese, G.; Conoci, S.; Parenti, R. Innovative Biomaterials for Tissue Engineering. In Biomaterial-Supported Tissue Reconstruction or Regeneration; IntechOpen: London, UK, 2019.

19. Sun, J.; Tan, H. Alginate-based biomaterials for regenerative medicine applications. Materials 2013, 6, 1285-1309. [CrossRef]

20. Sarker, B.; Boccaccini, A.R. Alginate Utilization in Tissue Engineering and Cell Therapy. In Alginates and Their Biomedical Applications; Springer: Singapore, 2018; pp. 121-155.

21. Li, X.; Chen, S.; Zhang, B.; Li, M.; Diao, K.; Zhang, Z.; Li, J.; Xu, Y.; Wang, X.; Chen, H. In situ injectable nano-composite hydrogel composed of curcumin, N,O-carboxymethyl chitosan and oxidized alginate for wound healing application. Int. J. Pharm. 2012, 437, 110-119. [CrossRef] [PubMed]

22. Kim, D.; Monaco, E.; Maki, A.; De Lima, A.S.; Kong, H.J.; Hurley, W.L.; Wheeler, M.B. Morphologic and transcriptomic comparison of adipose- and bone-marrow-derived porcine stem cells cultured in alginate hydrogels. Cell Tissue Res. 2010, 341, 359-370. [CrossRef] [PubMed]

23. Eschenhagen, T.; Fink, C.; Remmers, U.; Scholz, H.; Wattchow, J.; Weil, J.; Zimmermann, W.; Dohmen, H.H.; Schäfer, H.; Bishopric, N.; et al. Three-dimensional reconstitution of embryonic cardiomyocytes in a collagen matrix: A new heart muscle model system. FASEB J. 1997, 11, 683-694. [CrossRef]

24. Fink, C.; Ergün, S.; Kralisch, D.; Remmers, U.; Weil, J.; Eschenhagen, T. Chronic stretch of engineered heart tissue induces hypertrophy and functional improvement. FASEB J. 2000, 14, 669-679. [CrossRef]

25. Mooney, D.; Hansen, L.; Vacanti, J.; Langer, R.; Farmer, S.; Ingber, D. Switching from differentiation to growth in hepatocytes: Control by extracellular matrix. J. Cell. Physiol. 1992, 151, 497-505. [CrossRef]

26. Kim, B.S.; Mooney, D.J. Engineering smooth muscle tissue with a predefined structure. J. Biomed. Mater. Res. 1998, 41, 322-332. [CrossRef]

27. Badylak, S.F.; Arnoczky, S.; Plouhar, P.; Haut, R.; Mendenhall, V.; Clarke, R.; Horvath, C. Naturally occurring extracellular matrix as a scaffold for musculoskeletal repair. Clin. Orthop. Relat. Res. 1999, 367, S333-S343. [CrossRef] [PubMed] 
28. Van Amerongen, M.J.; Harmsen, M.C.; Petersen, A.H.; Kors, G.; Van Luyn, M.J.A. The enzymatic degradation of scaffolds and their replacement by vascularized extracellular matrix in the murine myocardium. Biomaterials 2006, 27, 2247-2257. [CrossRef]

29. Petreaca, M.; Martins-Green, M. Cell-Extracellular Matrix Interactions in Repair and Regeneration. In Principles of Regenerative Medicine; Academic Press: Cambridge, MA, USA, 2019; pp. 15-35.

30. Ethier, C.R.; Simmons, C.A. Introductory Biomechanics; Cambridge University Press: Cambridge, UK, 2007; ISBN 9780511809217.

31. Bertini, E.; Pepe, G. Collagen type VI and related disorders: Bethlem myopathy and Ullrich scleroatonic muscular dystrophy. Eur. J. Paediatr. Neurol. 2002, 6, 193-198. [CrossRef]

32. Bissell, M.J.; Hall, H.G.; Parry, G. How does the extracellular matrix direct gene expression? J. Theor. Biol. 1982, 99, 31-68. [CrossRef]

33. Bissell, M.J.; Barcellos-Hoff, M.H. The influence of extracellular matrix on gene expression: Is structure the message? J. Cell Sci. 1987, 343, 327-343. [CrossRef] [PubMed]

34. Caldeira, J.; Sousa, A.; Sousa, D.M.; Barros, D. Extracellular Matrix Constitution and Function for Tissue Regeneration and Repair; Elsevier Ltd.: Amsterdam, The Netherlands, 2018; ISBN 9780081008522.

35. Cao, Y.; Vacanti, J.P.; Paige, K.T.; Upton, J.; Vacanti, C.A. Transplantation of chondrocytes utilizing a polymer-cell construct to produce tissue-engineered cartilage in the shape of a human ear. Plast. Reconstr. Surg. 1997, 100, 297-304. [CrossRef] [PubMed]

36. Oberpenning, F.; Meng, J.; Yoo, J.J.; Atala, A. De Novo Reconstitution of a Functional Mammalian Urinary Bladder by Tissue Engineering. Nat. Biotechnol. 1999, 17, 149-155. [CrossRef] [PubMed]

37. Atala, A.; Bauer, S.B.; Soker, S.; Yoo, J.J.; Retik, A.B. Tissue-engineered autologous bladders for patients needing cystoplasty. Lancet 2006, 367, 1241-1246. [CrossRef]

38. Ott, H.C.; Matthiesen, T.S.; Goh, S.K.; Black, L.D.; Kren, S.M.; Netoff, T.I.; Taylor, D.A. Perfusion-decellularized matrix: Using nature's platform to engineer a bioartificial heart. Nat. Med. 2008, 14, 213-221. [CrossRef]

39. Martinez-Hernandez, A.; Amenta, P.S. The extracellular matrix in hepatic regeneration. FASEB J. 1995, 9 , $1401-1410$.

40. Uygun, B.E.; Soto-Gutierrez, A.; Yagi, H.; Izamis, M.L.; Guzzardi, M.A.; Shulman, C.; Milwid, J.; Kobayashi, N.; Tilles, A.; Berthiaume, F.; et al. Organ reengineering through development of a transplantable recellularized liver graft using decellularized liver matrix. Nat. Med. 2010, 16, 814-820. [CrossRef]

41. Jaramillo, M.; Yeh, H.; Yarmush, M.L.; Uygun, B.E. Decellularized human liver extracellular matrix (hDLM)-mediated hepatic differentiation of human induced pluripotent stem cells (hIPSCs). J. Tissue Eng. Regen. Med. 2018, 12, e1962-e1973. [CrossRef]

42. Devalliere, J.; Chen, Y.; Dooley, K.; Yarmush, M.L.; Uygun, B.E. Improving functional re-endothelialization of acellular liver scaffold using REDV cell-binding domain. Acta Biomater. 2018, 78, 151-164. [CrossRef]

43. Soto-Gutierrez, A.; Zhang, L.; Medberry, C.; Fukumitsu, K.; Faulk, D.; Jiang, H.; Reing, J.; Gramignoli, R.; Komori, J.; Ross, M.; et al. A whole-organ regenerative medicine approach for liver replacement. Tissue Eng. Part C Methods 2011, 17, 677-686. [CrossRef]

44. Miromatrix Medical Inc. Available online: https://www.miromatrix.com/ (accessed on 2 June 2020).

45. Technology Platform/TRS-Tissue Regeneration Systems. Available online: https:/tissuesys.com/technology/ (accessed on 2 June 2020).

46. Rokit Healthcare, Inc. Aging is Disease. Available online: http://rokithealthcare.com/ (accessed on 2 June 2020).

47. Abolbashari, M.; Agcaoili, S.M.; Lee, M.K.; Ko, I.K.; Aboushwareb, T.; Jackson, J.D.; Yoo, J.J.; Atala, A. Repopulation of porcine kidney scaffold using porcine primary renal cells. Acta Biomater. 2016, 29, 52-61. [CrossRef] [PubMed]

48. Ott, H.C.; Clippinger, B.; Conrad, C.; Schuetz, C.; Pomerantseva, I.; Ikonomou, L.; Kotton, D.; Vacanti, J.P. Regeneration and orthotopic transplantation of a bioartificial lung. Nat. Med. 2010, 16, 927-933. [CrossRef]

49. Gilpin, S.E.; Guyette, J.P.; Gonzalez, G.; Ren, X.; Asara, J.M.; Mathisen, D.J.; Vacanti, J.P.; Ott, H.C. Perfusion decellularization of human and porcine lungs: Bringing the matrix to clinical scale. J. Heart Lung Transplant. 2014, 33, 298-308. [CrossRef] [PubMed]

50. Chia, H.N.; Wu, B.M. Recent advances in 3D printing of biomaterials. J. Biol. Eng. 2015, 9, 4. [CrossRef] [PubMed] 
51. Bishop, E.S.; Mostafa, S.; Pakvasa, M.; Luu, H.H.; Lee, M.J.; Wolf, J.M.; Ameer, G.A.; He, T.C.; Reid, R.R. 3-D bioprinting technologies in tissue engineering and regenerative medicine: Current and future trends. Genes Dis. 2017, 4, 185-195. [CrossRef]

52. Kang, H.W.; Lee, S.J.; Ko, I.K.; Kengla, C.; Yoo, J.J.; Atala, A. A 3D bioprinting system to produce human-scale tissue constructs with structural integrity. Nat. Biotechnol. 2016, 34, 312-319. [CrossRef]

53. Nakamura, M.; Iwanaga, S.; Henmi, C.; Arai, K.; Nishiyama, Y. Biomatrices and biomaterials for future developments of bioprinting and biofabrication. Biofabrication 2010, 2, 014110. [CrossRef]

54. Hinton, T.J.; Jallerat, Q.; Palchesko, R.N.; Park, J.H.; Grodzicki, M.S.; Shue, H.J.; Ramadan, M.H.; Hudson, A.R.; Feinberg, A.W. Three-dimensional printing of complex biological structures by freeform reversible embedding of suspended hydrogels. Sci. Adv. 2015, 1, e1500758. [CrossRef]

55. Grigoryan, B.; Paulsen, S.J.; Corbett, D.C.; Sazer, D.W.; Fortin, C.L.; Zaita, A.J.; Greenfield, P.T.; Calafat, N.J.; Gounley, J.P.; Ta, A.H.; et al. Multivascular networks and functional intravascular topologies within biocompatible hydrogels. Science 2019, 364, 458-464. [CrossRef]

56. Mandrycky, C.; Phong, K.; Zheng, Y. Tissue engineering toward organ-specific regeneration and disease modeling. MRS Commun. 2017, 7, 332-347. [CrossRef]

57. Mazza, G.; Rombouts, K.; Rennie Hall, A.; Urbani, L.; Vinh Luong, T.; Al-Akkad, W.; Longato, L.; Brown, D.; Maghsoudlou, P.; Dhillon, A.P.; et al. Decellularized human liver as a natural 3D-scaffold for liver bioengineering and transplantation. Sci. Rep. 2015, 5, 13079. [CrossRef] [PubMed]

58. Lee, A.; Hudson, A.R.; Shiwarski, D.J.; Tashman, J.W.; Hinton, T.J.; Yerneni, S.; Bliley, J.M.; Campbell, P.G.; Feinberg, A.W. 3D bioprinting of collagen to rebuild components of the human heart. Science 2019, 365, 482-487. [CrossRef] [PubMed]

59. Gungor-Ozkerim, P.S.; Inci, I.; Zhang, Y.S.; Khademhosseini, A.; Dokmeci, M.R. Bioinks for 3D bioprinting: An overview. Biomater. Sci. 2018, 6, 915-946. [CrossRef] [PubMed]

60. Traphagen, S.; Yelick, P.C. Reclaiming a natural beauty: Whole-organ engineering with natural extracellular materials. Regen. Med. 2009, 747-758. [CrossRef]

61. Londono, R.; Badylak, S.F. Biologic Scaffolds for Regenerative Medicine: Mechanisms of In vivo Remodeling. Ann. Biomed. Eng. 2015, 43, 577-592. [CrossRef]

62. Gilpin, S.E.; Ren, X.; Okamoto, T.; Guyette, J.P.; Mou, H.; Rajagopal, J.; Mathisen, D.J.; Vacanti, J.P.; Ott, H.C. Enhanced lung epithelial specification of human induced pluripotent stem cells on decellularized lung matrix. Ann. Thorac. Surg. 2014, 98, 1721-1729. [CrossRef]

63. Baptista, P.M.; Siddiqui, M.M.; Lozier, G.; Rodriguez, S.R.; Atala, A.; Soker, S. The use of whole organ decellularization for the generation of a vascularized liver organoid. Hepatology 2011, 53, 604-617. [CrossRef]

64. Huling, J.C.; Atala, A.; Yoo, J.J. Decellularized Whole Organ Scaffolds for the Regeneration of Kidneys; Elsevier Inc.: Amsterdam, The Netherlands, 2015; ISBN 9780128004388.

65. Faulk, D.M.; Wildemann, J.D.; Badylak, S.F. Decellularization and cell seeding of whole liver biologic scaffolds composed of extracellular matrix. J. Clin. Exp. Hepatol. 2015, 5, 69-80. [CrossRef]

66. Jank, B.J.; Goverman, J.; Guyette, J.P.; Charest, J.M.; Randolph, M.; Gaudette, G.R.; Gershlak, J.R.; Purschke, M.; Javorsky, E.; Nazarian, R.M.; et al. Creation of a Bioengineered Skin Flap Scaffold with a Perfusable Vascular Pedicle. Tissue Eng. Part A 2017, 23, 696-707. [CrossRef]

67. Obata, T.; Tsuchiya, T.; Akita, S.; Kawahara, T.; Matsumoto, K.; Miyazaki, T.; Masumoto, H.; Kobayashi, E.; Niklason, L.E.; Nagayasu, T. Utilization of Natural Detergent Potassium Laurate for Decellularization in Lung Bioengineering. Tissue Eng. Part C Methods 2019, 25, 459-471. [CrossRef]

68. Faulk, D.M.; Johnson, S.A.; Zhang, L.; Badylak, S.F. Role of the extracellular matrix in whole organ engineering. J. Cell. Physiol. 2014, 229, 984-989. [CrossRef] [PubMed]

69. Yagi, H.; Soto-Gutierrez, A.; Kitagawa, Y. Whole-organ re-engineering: A regenerative medicine approach in digestive surgery for organ replacement. Surg. Today 2013, 43, 587-594. [CrossRef]

70. Keane, T.J.; DeWard, A.; Londono, R.; Saldin, L.T.; Castleton, A.A.; Carey, L.; Nieponice, A.; Lagasse, E.; Badylak, S.F. Tissue-Specific Effects of Esophageal Extracellular Matrix. Tissue Eng. Part A 2015, 21, 2293-2300. [CrossRef]

71. Macchiarini, P.; Jungebluth, P.; Go, T.; Asnaghi, M.A.; Rees, L.E.; Cogan, T.A.; Dodson, A.; Martorell, J.; Bellini, S.; Parnigotto, P.P.; et al. Clinical transplantation of a tissue-engineered airway. Lancet 2008, 372, 2023-2030. [CrossRef] 
72. Bracaglia, L.G.; Fisher, J.P. Extracellular Matrix-Based Biohybrid Materials for Engineering Compliant, Matrix-Dense Tissues. Adv. Healthc. Mater. 2015, 4, 2475-2487. [CrossRef]

73. Heydarkhan-Hagvall, S.; Schenke-Layland, K.; Dhanasopon, A.P.; Rofail, F.; Smith, H.; Wu, B.M.; Shemin, R.; Beygui, R.E.; MacLellan, W.R. Three-dimensional electrospun ECM-based hybrid scaffolds for cardiovascular tissue engineering. Biomaterials 2008, 29, 2907-2914. [CrossRef]

74. He, W.; Yong, T.; Teo, W.E.; Ma, Z.; Ramakrishna, S. Fabrication and endothelialization of collagen-blended biodegradable polymer nanofibers: Potential vascular graft for blood vessel tissue engineering. Tissue Eng. 2005, 11, 1574-1588. [CrossRef] [PubMed]

75. Barnes, C.P.; Sell, S.A.; Boland, E.D.; Simpson, D.G.; Bowlin, G.L. Nanofiber technology: Designing the next generation of tissue engineering scaffolds. Adv. Drug Deliv. Rev. 2007, 59, 1413-1433. [CrossRef] [PubMed]

76. Kumbar, S.G.; James, R.; Nukavarapu, S.P.; Laurencin, C.T. Electrospun nanofiber scaffolds: Engineering soft tissues. Biomed. Mater. 2008, 3, 034002. [CrossRef]

77. Ramanathan, G.; Sobhana, L.; Sobhanadhas, S.; Felciya, G.; Jeyakumar, S.; Devi, V.; Sivagnanam, U.T.; Fardim, P. Fabrication of biohybrid cellulose acetate-collagen bilayer matrices as nanofibrous spongy dressing material for wound healing application. Biomacromolecules 2020, 21, 2512-2524. [CrossRef]

78. Li, X.; Guo, Y.; Ziegler, K.R.; Model, L.S.; Eghbalieh, S.D.D.; Brenes, R.A.; Kim, S.T.; Shu, C.; Dardik, A. Current usage and future directions for the bovine pericardial patch. Ann. Vasc. Surg. 2011, 25, 561-568. [CrossRef] [PubMed]

79. Chang, C.C.; Boland, E.D.; Williams, S.K.; Hoying, J.B. Direct-write bioprinting three-dimensional biohybrid systems for future regenerative therapies. J. Biomed. Mater. Res. Part B Appl. Biomater. 2011, 98, 160-170. [CrossRef] [PubMed]

80. Zhu, J. Bioactive modification of poly(ethylene glycol) hydrogels for tissue engineering. Biomaterials 2010, 31, 4639-4656. [CrossRef] [PubMed]

81. Jung, J.P.; Sprangers, A.J.; Byce, J.R.; Su, J.; Squirrell, J.M.; Messersmith, P.B.; Eliceiri, K.W.; Ogle, B.M. ECM-incorporated hydrogels cross-linked via native chemical ligation to engineer stem cell microenvironments. Biomacromolecules 2013, 14, 3102-3111. [CrossRef]

82. Jammalamadaka, U.; Tappa, K. Recent advances in biomaterials for 3D printing and tissue engineering. J. Funct. Biomater. 2018, 9, 22. [CrossRef]

83. Do, A.V.; Khorsand, B.; Geary, S.M.; Salem, A.K. 3D Printing of Scaffolds for Tissue Regeneration Applications. Adv. Healthc. Mater. 2015, 4, 1742-1762. [CrossRef]

84. Ozbolat, I.T. Bioprinting scale-up tissue and organ constructs for transplantation. Trends Biotechnol. 2015, 33, 395-400. [CrossRef]

85. Kodama, H. Automatic method for fabricating a three-dimensional plastic model with photo-hardening polymer. Rev. Sci. Instrum. 1981, 52, 1770-1773. [CrossRef]

86. Hull, C.W. Arcadia, and Calif. United States Patent (19) no. 19, 8 August 1984.

87. Deckard, C.R. Method and Apparatus for Producing Parts by Selective Sintering. U.S. Patent 4,863,538, 5 September 1989.

88. Crump, S. Apparatus and Method for Creating Three-Dimensional Objects. U.S. Patent 5,121,329, 9 June 1992.

89. Ventola, C.L. Medical Applications for 3D Printing: Current and Projected Uses. Pharm. Ther. 2014, 39, 704-711.

90. Sudarmadji, N.; Tan, J.Y.; Leong, K.F.; Chua, C.K.; Loh, Y.T. Investigation of the mechanical properties and porosity relationships in selective laser-sintered polyhedral for functionally graded scaffolds. Acta Biomater. 2011, 7, 530-537. [CrossRef] [PubMed]

91. Williams, J.M.; Adewunmi, A.; Schek, R.M.; Flanagan, C.L.; Krebsbach, P.H.; Feinberg, S.E.; Hollister, S.J.; Das, S. Bone tissue engineering using polycaprolactone scaffolds fabricated via selective laser sintering. Biomaterials 2005, 26, 4817-4827. [CrossRef] [PubMed]

92. Noor, N.; Shapira, A.; Edri, R.; Gal, I.; Wertheim, L.; Dvir, T. 3D Printing of Personalized Thick and Perfusable Cardiac Patches and Hearts. Adv. Sci. 2019, 6, 1900344. [CrossRef] [PubMed]

93. Miri, A.K.; Nieto, D.; Iglesias, L.; Goodarzi Hosseinabadi, H.; Maharjan, S.; Ruiz-Esparza, G.U.; Khoshakhlagh, P.; Manbachi, A.; Dokmeci, M.R.; Chen, S.; et al. Microfluidics-Enabled Multimaterial Maskless Stereolithographic Bioprinting. Adv. Mater. 2018, 30, 1-9. [CrossRef] [PubMed] 
94. Cristobal, A.; van den Toorn, H.W.P.; van de Wetering, M.; Clevers, H.; Heck, A.J.R.; Mohammed, S. Personalized Proteome Profiles of Healthy and Tumor Human Colon Organoids Reveal Both Individual Diversity and Basic Features of Colorectal Cancer. Cell Rep. 2017, 18, 263-274. [CrossRef]

95. Kim, Y.; Kim, H.; Ko, U.H.; Oh, Y.; Lim, A.; Sohn, J.W.; Shin, J.H.; Kim, H.; Han, Y.M. Islet-like organoids derived from human pluripotent stem cells efficiently function in the glucose responsiveness in vitro and in vivo. Sci. Rep. 2016, 6, 1-13. [CrossRef]

96. Hohwieler, M.; Illing, A.; Hermann, P.C.; Mayer, T.; Stockmann, M.; Perkhofer, L.; Eiseler, T.; Antony, J.S.; Müller, M.; Renz, S.; et al. Human pluripotent stem cell-derived acinar/ductal organoids generate human pancreas upon orthotopic transplantation and allow disease modelling. Gut 2017, 66, 473-486. [CrossRef]

97. Wainwright, J.M.; Czajka, C.A.; Patel, U.B.; Freytes, D.O.; Tobita, K.; Gilbert, T.W.; Badylak, S.F. Preparation of cardiac extracellular matrix from an intact porcine heart. Tissue Eng. Part C Methods 2010, 16, 525-532. [CrossRef]

98. Guyette, J.P.; Charest, J.M.; Mills, R.W.; Jank, B.J.; Moser, P.T.; Gilpin, S.E.; Gershlak, J.R.; Okamoto, T.; Gonzalez, G.; Milan, D.J.; et al. Bioengineering Human Myocardium on Native Extracellular Matrix. Circ. Res. 2016, 118, 56-72. [CrossRef]

99. Taylor, D.A.; Frazier, O.H.; Elgalad, A.; Hochman-Mendez, C.; Sampaio, L.C. Building a Total Bioartificial Heart: Harnessing Nature to Overcome the Current Hurdles. Artif. Organs 2018, 42, 970-982. [CrossRef]

100. Sánchez, P.L.; Fernández-Santos, M.E.; Espinosa, M.A.; González-Nicolas, M.A.; Acebes, J.R.; Costanza, S.; Moscoso, I.; Rodríguez, H.; García, J.; Romero, J.; et al. Data from acellular human heart matrix. Data Brief 2016, 8, 211-219. [CrossRef]

101. Ko, I.K.; Peng, L.; Peloso, A.; Smith, C.J.; Dhal, A.; Deegan, D.B.; Zimmerman, C.; Clouse, C.; Zhao, W.; Shupe, T.D.; et al. Bioengineered transplantable porcine livers with re-endothelialized vasculature. Biomaterials 2015, 40, 72-79. [CrossRef]

102. Hussein, K.H.; Park, K.M.; Kang, K.S.; Woo, H.M. Heparin-gelatin mixture improves vascular reconstruction efficiency and hepatic function in bioengineered livers. Acta Biomater. 2016, 38, 82-93. [CrossRef] [PubMed]

103. Nakamura, T.; Mizuno, S. The discovery of Hepatocyte Growth Factor (HGF) and its significance for cell biology, life sciences and clinical medicine. Proc. Jpn. Acad. Ser. B 2010, 86, 588-610. [CrossRef] [PubMed]

104. Mao, S.A. Sustained In Vivo Perfusion of a Re-Endothelialized Tissue Engineered Porcine Liver. Int. J. Transplant. Res. Med. 2017, 3, 1-9. [CrossRef]

105. Schumacher, J.D.; Guo, G.L. Regulation of Hepatic Stellate Cells and Fibrogenesis by Fibroblast Growth Factors. BioMed Res. Int. 2016, 2016, 8323747. [CrossRef]

106. Orlando, G.; Booth, C.; Wang, Z.; Totonelli, G.; Ross, C.L.; Moran, E.; Salvatori, M.; Maghsoudlou, P.; Turmaine, M.; Delario, G.; et al. Discarded human kidneys as a source of ECM scaffold for kidney regeneration technologies. Biomaterials 2013, 34, 5915-5925. [CrossRef] [PubMed]

107. Ross, E.A.; Williams, M.J.; Hamazaki, T.; Terada, N.; Clapp, W.L.; Adin, C.; Ellison, G.W.; Jorgensen, M.; Batich, C.D. Embryonic stem cells proliferate and differentiate when seeded into kidney scaffolds. J. Am. Soc. Nephrol. 2009, 20, 2338-2347. [CrossRef]

108. Song, J.J.; Guyette, J.P.; Gilpin, S.E.; Gonzalez, G.; Vacanti, J.P.; Ott, H.C. Regeneration and experimental orthotopic transplantation of a bioengineered kidney. Nat. Med. 2013, 19, 646-651. [CrossRef]

109. Kajbafzadeh, A.M.; Khorramirouz, R.; Nabavizadeh, B.; Ladi Seyedian, S.S.; Akbarzadeh, A.; Heidari, R.; Masoumi, A.; Azizi, B.; Seyed Hossein Beigi, R. Whole organ sheep kidney tissue engineering and in vivo transplantation: Effects of perfusion-based decellularization on vascular integrity. Mater. Sci. Eng. C 2019, 98, 392-400. [CrossRef] [PubMed]

110. Katari, R.; Peloso, A.; Zambon, J.P.; Soker, S.; Stratta, R.J.; Atala, A.; Orlando, G. Renal bioengineering with scaffolds generated from human kidneys. Nephron Exp. Nephrol. 2014, 126, 119-124. [CrossRef]

111. Ciampi, O.; Bonandrini, B.; Derosas, M.; Conti, S.; Rizzo, P.; Benedetti, V.; Figliuzzi, M.; Remuzzi, A.; Benigni, A.; Remuzzi, G.; et al. Engineering the vasculature of decellularized rat kidney scaffolds using human induced pluripotent stem cell-derived endothelial cells. Sci. Rep. 2019, 9, 1-10. [CrossRef] [PubMed]

112. Ali, M.; Anil Kumar, P.R.; Yoo, J.J.; Zahran, F.; Atala, A.; Lee, S.J. A Photo-Crosslinkable Kidney ECM-Derived Bioink Accelerates Renal Tissue Formation. Adv. Healthc. Mater. 2019, 8, 1-10. [CrossRef] [PubMed]

113. Denizet, G.; Calame, P.; Lihoreau, T.; Kleinclauss, F.; Aubry, S. 3D multi-tissue printing for kidney transplantation. Quant. Imaging Med. Surg. 2019, 9, 101. [CrossRef] [PubMed] 
114. Homan, K.A.; Kolesky, D.B.; Skylar-Scott, M.A.; Herrmann, J.; Obuobi, H.; Moisan, A.; Lewis, J.A. Bioprinting of 3D Convoluted Renal Proximal Tubules on Perfusable Chips. Sci. Rep. 2016, 6, 1-13. [CrossRef]

115. Carreno-Galeano, G.; Ali, M.; Jackson, J.; Yoo, J.; Lee, S.J.; Atala, A. 3D Bioprinted Renal Tissue Constructs Using a Novel Kidney ECM-Derived Bioink. J. Urol. 2020, 203, e775. [CrossRef]

116. Petersen, T.H.; Calle, E.A.; Zhao, L.; Lee, E.J.; Gui, L.; Raredon, M.S.B.; Gavrilov, K.; Yi, T.; Zhuang, Z.W.; Breuer, C.; et al. Tissue-engineered lungs for in vivo implantation. Science 2010, 329, 538-541. [CrossRef]

117. Zhou, H.; Kitano, K.; Ren, X.; Rajab, T.K.; Wu, M.; Gilpin, S.E.; Wu, T.; Baugh, L.; Black, L.D.; Mathisen, D.J.; et al. Bioengineering Human Lung Grafts on Porcine Matrix. Ann. Surg. 2018, 267, 590-598. [CrossRef]

118. Urbano, J.J.; Da Palma, R.K.; De Lima, F.M.; Fratini, P.; Guimaraes, L.L.; Uriarte, J.J.; Alvarenga, L.H.; Miglino, M.A.; Vieira, R.D.P.; Prates, R.A.; et al. Effects of two different decellularization routes on the mechanical properties of decellularized lungs. PLOS ONE 2017, 12, e0178696. [CrossRef]

119. O’Neill, J.D.; Anfang, R.; Anandappa, A.; Costa, J.; Javidfar, J.; Wobma, H.M.; Singh, G.; Freytes, D.O.; Bacchetta, M.D.; Sonett, J.R.; et al. Decellularization of human and porcine lung tissues for pulmonary tissue engineering. Ann. Thorac. Surg. 2013, 96, 1046-1056. [CrossRef]

120. Balestrini, J.L.; Gard, A.L.; Liu, A.; Leiby, K.L.; Schwan, J.; Kunkemoeller, B.; Calle, E.A.; Sivarapatna, A.; Lin, T.; Dimitrievska, S.; et al. Production of decellularized porcine lung scaffolds for use in tissue engineering. Integr. Biol. 2015, 7, 1598-1610. [CrossRef]

121. Yuan, Y.; Engler, A.J.; Raredon, M.S.; Le, A.; Baevova, P.; Yoder, M.C.; Niklason, L.E. Epac agonist improves barrier function in iPSC-derived endothelial colony forming cells for whole organ tissue engineering. Biomaterials 2019, 200, 25-34. [CrossRef] [PubMed]

122. Nichols, J.E.; La Francesca, S.; Niles, J.A.; Vega, S.P.; Argueta, L.B.; Frank, L.; Christiani, D.C.; Pyles, R.B.; Himes, B.E.; Zhang, R.; et al. Production and transplantation of bioengineered lung into a large-animal model. Sci. Transl. Med. 2018, 10, eaao3926. [CrossRef] [PubMed]

123. Citro, A.; Ott, H.C. Can We Re-Engineer the Endocrine Pancreas? Curr. Diab. Rep. 2018, 18, 1-7. [CrossRef] [PubMed]

124. Goh, S.K.; Bertera, S.; Olsen, P.; Candiello, J.E.; Halfter, W.; Uechi, G.; Balasubramani, M.; Johnson, S.A.; Sicari, B.M.; Kollar, E.; et al. Perfusion-decellularized pancreas as a natural 3D scaffold for pancreatic tissue and whole organ engineering. Biomaterials 2013, 34, 6760-6772. [CrossRef] [PubMed]

125. Mirmalek-Sani, S.H.; Orlando, G.; McQuilling, J.P.; Pareta, R.; Mack, D.L.; Salvatori, M.; Farney, A.C.; Stratta, R.J.; Atala, A.; Opara, E.C.; et al. Porcine pancreas extracellular matrix as a platform for endocrine pancreas bioengineering. Biomaterials 2013, 34, 5488-5495. [CrossRef]

126. Peloso, A.; Urbani, L.; Cravedi, P.; Katari, R.; Maghsoudlou, P.; Fallas, M.E.A.; Sordi, V.; Citro, A.; Purroy, C.; Niu, G.; et al. The human pancreas as a source of protolerogenic extracellular matrix scaffold for a new-generation bioartificial endocrine pancreas. Ann. Surg. 2016, 264, 169-179. [CrossRef]

127. Hashemi, J.; Pasalar, P.; Soleimani, M.; Khorramirouz, R.; Fendereski, K.; Enderami, S.E.; Kajbafzadeh, A.M. Application of a novel bioreactor for in vivo engineering of pancreas tissue. J. Cell. Physiol. 2018, 233, 3805-3816. [CrossRef] [PubMed]

128. Hashemi, J.; Pasalar, P.; Soleimani, M.; Arefian, E.; Khorramirouz, R.; Akbarzadeh, A.; Ghorbani, F.; Enderami, S.E.; Kajbafzadeh, A.M. Decellularized pancreas matrix scaffolds for tissue engineering using ductal or arterial catheterization. Cells Tissues Organs 2018, 205, 72-84. [CrossRef] [PubMed]

129. Pagliuca, F.W.; Millman, J.R.; Gürtler, M.; Segel, M.; Van Dervort, A.; Ryu, J.H.; Peterson, Q.P.; Greiner, D.; Melton, D.A. Generation of functional human pancreatic $\beta$ cells in vitro. Cell 2014, 159, 428-439. [CrossRef]

130. Vegas, A.J.; Veiseh, O.; Gürtler, M.; Millman, J.R.; Pagliuca, F.W.; Bader, A.R.; Doloff, J.C.; Li, J.; Chen, M.; Olejnik, K.; et al. Long-term glycemic control using polymer-encapsulated human stem cell-derived beta cells in immune-competent mice. Nat. Med. 2016, 22, 306-311. [CrossRef] [PubMed]

131. Deuse, T.; Hu, X.; Gravina, A.; Wang, D.; Tediashvili, G.; De, C.; Thayer, W.O.; Wahl, A.; Garcia, J.V.; Reichenspurner, H.; et al. Hypoimmunogenic derivatives of induced pluripotent stem cells evade immune rejection in fully immunocompetent allogeneic recipients. Nat. Biotechnol. 2019, 37, 252-258. [CrossRef]

132. Lanza, R.; Russell, D.W.; Nagy, A. Engineering universal cells that evade immune detection. Nat. Rev. Immunol. 2019, 19, 723-733. [CrossRef]

133. Piechota, H.J.; Dahms, S.E.; Nunes, L.S.; Dahiya, R.; Lue, T.F.; Tanagho, E.A. In vitro functional properties of the rat bladder regenerated by the bladder acellular matrix graft. J. Urol. 1998, 159, 1717-1724. [CrossRef] [PubMed] 
134. Olsen, L.; Bowald, S.; Busch, C.; Carlsten, J.; Eriksson, I. Urethral reconstruction with a new synthetic absorbable device: An experimental study. Scand. J. Urol. Nephrol. 1992, 26, 323-326. [CrossRef] [PubMed]

135. Eberli, D.; Filho, L.F.; Atala, A.; Yoo, J.J. Composite scaffolds for the engineering of hollow organs and tissues. Methods 2009, 47, 109-115. [CrossRef] [PubMed]

136. Song, L.; Murphy, S.V.; Yang, B.; Xu, Y.; Zhang, Y.; Atala, A. Bladder acellular matrix and its application in bladder augmentation. Tissue Eng. Part B Rev. 2014, 20, 163-172. [CrossRef] [PubMed]

137. Joseph, D.B.; Borer, J.G.; De Filippo, R.E.; Hodges, S.J.; McLorie, G.A. Autologous cell seeded biodegradable scaffold for augmentation cystoplasty: Phase II study in children and adolescents with spina bifida. J. Urol. 2014, 191, 1389-1395. [CrossRef]

138. Zhe, Z.; Jun, D.; Yang, Z.; Mingxi, X.; Ke, Z.; Ming, Z.; Zhong, W.; Mujun, L. Bladder Acellular Matrix Grafts Seeded with Adipose-Derived Stem Cells and Incubated Intraperitoneally Promote the Regeneration of Bladder Smooth Muscle and Nerve in a Rat Model of Bladder Augmentation. Stem Cells Dev. 2016, 25, 405-414. [CrossRef]

139. Moreno-Manzano, V.; Mellado-López, M.; Morera-Esteve, M.J.; Alastrue-Agudo, A.; Bisbal-Velasco, V.; Forteza-Vila, J.; Serrano-Aroca, Á.; Vera-Donoso, C.D. Human adipose-derived mesenchymal stem cells accelerate decellularized neobladder regeneration. Regen. Biomater. 2020, 7, 161-169. [CrossRef]

140. Sander, E.A.; Lynch, K.A.; Boyce, S.T. Development of the Mechanical Properties of Engineered Skin Substitutes after Grafting to Full-Thickness Wounds. J. Biomech. Eng. 2014, 136, 1-7. [CrossRef]

141. Itoh, M.; Umegaki-Arao, N.; Guo, Z.; Liu, L.; Higgins, C.A.; Christiano, A.M. Generation of 3D Skin Equivalents Fully Reconstituted from Human Induced Pluripotent Stem Cells (iPSCs). PLoS ONE 2013, 8, e77673. [CrossRef] [PubMed]

142. Baltazar, T.; Merola, J.; Catarino, C.; Xie, C.B.; Kirkiles-Smith, N.C.; Lee, V.; Hotta, S.; Dai, G.; Xu, X.; Ferreira, F.C.; et al. Three Dimensional Bioprinting of a Vascularized and Perfusable Skin Graft Using Human Keratinocytes, Fibroblasts, Pericytes, and Endothelial Cells. Tissue Eng. Part A 2020, 26, 227-238. [CrossRef] [PubMed]

143. Liu, N.; Huang, S.; Yao, B.; Xie, J.; Wu, X.; Fu, X. 3D bioprinting matrices with controlled pore structure and release function guide in vitro self-organization of sweat gland. Sci. Rep. 2016, 6, 1-8. [CrossRef]

144. Parnigotto, P.P.; Marzaro, M.; Artusi, T.; Perrino, G.; Conconi, M.T. Short bowel syndrome: Experimental approach to increase intestinal surface in rats by gastric homologous acellular matrix. J. Pediatr. Surg. 2000, 35, 1304-1308. [CrossRef] [PubMed]

145. Chen, M.K.; Badylak, S.F. Small bowel tissue engineering using small intestinal submucosa as a scaffold. J. Surg. Res. 2001, 99, 352-358. [CrossRef] [PubMed]

146. Maemura, T.; Shin, M.; Kinoshita, M.; Majima, T.; Ishihara, M.; Saitoh, D.; Ichikura, T. A tissue-engineered stomach shows presence of proton pump and G-cells in a rat model, resulting in improved anemia following total gastrectomy. Artif. Organs 2008, 32, 234-239. [CrossRef]

147. Grikscheit, T.C.; Siddique, A.; Ochoa, E.R.; Srinivasan, A.; Alsberg, E.; Hodin, R.A.; Vacanti, J.P. Tissue-engineered small intestine improves recovery after massive small bowel resection. Ann. Surg. 2004, 240, 748-754. [CrossRef]

148. Grant, C.N.; Mojica, S.G.; Sala, F.G.; Ryan Hill, J.; Levin, D.E.; Speer, A.L.; Barthel, E.R.; Shimada, H.; Zachos, N.C.; Grikscheit, T.C. Human and mouse tissue-engineered small intestine both demonstrate digestive and absorptive function. Am. J. Physiol. Gastrointest. Liver Physiol. 2015, 308, G664-G677. [CrossRef]

149. Levin, D.E.; Barthel, E.R.; Speer, A.L.; Sala, F.G.; Hou, X.; Torashima, Y.; Grikscheit, T.C. Human tissue-engineered small intestine forms from postnatal progenitor cells. J. Pediatr. Surg. 2013, 48, 129-137. [CrossRef]

150. Nakatsu, H.; Ueno, T.; Oga, A.; Nakao, M.; Nishimura, T.; Kobayashi, S.; Masaaki, O. Influence of mesenchymal stem cells on stomach tissue engineering using small intestinal submucosa. J. Tissue Eng. Regen. Med. 2015, 9, 296-304. [CrossRef]

151. Kim, I.G.; Wu, Y.; Park, S.A.; Cho, H.; Choi, J.J.; Kwon, S.K.; Shin, J.W.; Chung, E.J. Tissue-engineered esophagus via bioreactor cultivation for circumferential esophageal reconstruction. Tissue Eng. Part A 2019, 25, 1478-1492. [CrossRef] [PubMed]

152. Dadhich, P.; Bohl, J.L.; Tamburrini, R.; Zakhem, E.; Scott, C.; Kock, N.; Mitchell, E.; Gilliam, J.; Bitar, K.N. BioSphincters to treat Fecal Incontinence in Nonhuman Primates. Sci. Rep. 2019, 9, 1-11. [CrossRef] 
153. Sullivan, D.C.; Mirmalek-Sani, S.H.; Deegan, D.B.; Baptista, P.M.; Aboushwareb, T.; Atala, A.; Yoo, J.J. Decellularization methods of porcine kidneys for whole organ engineering using a high-throughput system. Biomaterials 2012, 33, 7756-7764. [CrossRef] [PubMed]

154. Bonandrini, B.; Figliuzzi, M.; Papadimou, E.; Morigi, M.; Perico, N.; Casiraghi, F.; Dipl, C.; Sangalli, F.; Conti, S.; Benigni, A.; et al. Recellularization of well-preserved acellular kidney scaffold using embryonic stem cells. Tissue Eng. Part A 2014, 20, 1486-1498. [CrossRef] [PubMed]

155. Sabetkish, S.; Kajbafzadeh, A.M.; Sabetkish, N.; Khorramirouz, R.; Akbarzadeh, A.; Seyedian, S.L.; Pasalar, P.; Orangian, S.; Hossein Beigi, R.S.; Aryan, Z.; et al. Whole-organ tissue engineering: Decellularization and recellularization of three-dimensional matrix liver scaffolds. J. Biomed. Mater. Res. Part A 2015, 103, 1498-1508. [CrossRef]

156. Kitano, K.; Schwartz, D.M.; Zhou, H.; Gilpin, S.E.; Wojtkiewicz, G.R.; Ren, X.; Sommer, C.A.; Capilla, A.V.; Mathisen, D.J.; Goldstein, A.M.; et al. Bioengineering of functional human induced pluripotent stem cell-derived intestinal grafts. Nat. Commun. 2017, 8, 1-13. [CrossRef]

157. Leuning, D.G.; Witjas, F.M.R.; Maanaoui, M.; de Graaf, A.M.A.; Lievers, E.; Geuens, T.; Avramut, C.M.; Wiersma, L.E.; van den Berg, C.W.; Sol, W.M.P.J.; et al. Vascular bioengineering of scaffolds derived from human discarded transplant kidneys using human pluripotent stem cell-derived endothelium. Am. J. Transplant. 2019, 19, 1328-1343. [CrossRef]

158. Willemse, J.; Verstegen, M.M.A.; Vermeulen, A.; Schurink, I.J.; Roest, H.P.; van der Laan, L.J.W.; de Jonge, J. Fast, robust and effective decellularization of whole human livers using mild detergents and pressure controlled perfusion. Mater. Sci. Eng. C 2020, 108, 110200. [CrossRef]

159. Anazawa, T.; Okajima, H.; Masui, T.; Uemoto, S. Current state and future evolution of pancreatic islet transplantation. Ann. Gastroenterol. Surg. 2019, 3, 34-42. [CrossRef] [PubMed]

160. Van Den Bos, E.J.; Van Der Giessen, W.J.; Duncker, D.J. Cell transplantation for cardiac regeneration: Where do we stand? Neth. Heart J. 2008, 16, 88-95. [CrossRef] [PubMed]

161. Wang, S.; Wu, J.; Liu, G.H. First stem cell transplantation to regenerate human lung. Protein Cell 2018, 9, 244-245. [CrossRef] [PubMed]

162. Di Foggia, V.; Makwana, P.; Ali, R.R.; Sowden, J.C. Induced pluripotent stem cell therapies for degenerative disease of the outer retina: Disease modeling and cell replacement. J. Ocul. Pharmacol. Ther. 2016, 32, 240-252. [CrossRef] [PubMed]

163. Foster, E.D.; Bridges, N.D.; Feurer, I.D.; Eggerman, T.L.; Hunsicker, L.G.; Alejandro, R. Improved Health-Related Quality of Life in a Phase 3 Islet Transplantation Trial in Type 1 Diabetes Complicated by Severe Hypoglycemia. Diabetes Care 2018, 41, 1001-1008. [CrossRef] [PubMed]

164. Jain, A.; Bansal, R. Applications of regenerative medicine in organ transplantation. J. Pharm. Bioallied Sci. 2015, 7, 188-194. [CrossRef]

165. Boehler, R.M.; Graham, J.G.; Shea, L.D. Tissue engineering tools for modulation of the immune response. Biotechniques 2011, 51, 239-254. [CrossRef]

166. Andorko, J.I.; Jewell, C.M. Designing biomaterials with immunomodulatory properties for tissue engineering and regenerative medicine. Bioeng. Transl. Med. 2017, 2, 139-155. [CrossRef]

167. Von Der Mark, K.; Gauss, V.; Von Der Mark, H.; Müller, P. Relationship between cell shape and type of collagen synthesised as chondrocytes lose their cartilage phenotype in culture. Nature 1977, 267, 531-532. [CrossRef]

168. Benya, P.D.; Shaffer, J.D. Dedifferentiated chondrocytes reexpress the differentiated collagen phenotype when cultured in agarose gels. Cell 1982, 30, 215-224. [CrossRef]

169. Ravi, M.; Paramesh, V.; Kaviya, S.R.; Anuradha, E.; Paul Solomon, F.D. 3D cell culture systems: Advantages and applications. J. Cell. Physiol. 2015, 230, 16-26. [CrossRef]

170. Bissell, M.J. The Differentiated State of Normal and Malignant Cells or How to Define a "Normal" Cell in Culture. In International Review of Cytology; Academic Press: Cambridge, MA, USA, 1981; Volume 70, ISBN 0123644704.

171. Hirschi, K.K.; Li, S.; Roy, K. Induced Pluripotent Stem Cells for Regenerative Medicine. Annu. Rev. Biomed. Eng. 2014, 16, 277-294. [CrossRef]

172. Nguyen, H.T.; Jacobs, K.; Spits, C. Human pluripotent stem cells in regenerative medicine: Where do we stand? Reproduction 2018, 156, R143-R153. [CrossRef] [PubMed] 
173. Thomson, J.A. Embryonic stem cell lines derived from human blastocysts. Science 1998, 282, $1145-1147$. [CrossRef] [PubMed]

174. Studer. Stem Cell in Disease Review. Ethn. Dis. 2010, 20, 1-26. [CrossRef]

175. Takahashi, K.; Yamanaka, S. Induction of Pluripotent Stem Cells from Mouse Embryonic and Adult Fibroblast Cultures by Defined Factors. Cell 2006, 126, 663-676. [CrossRef] [PubMed]

176. Lin, Y.C.; Leu, S.; Sun, C.K.; Yen, C.H.; Kao, Y.H.; Chang, L.T.; Tsai, T.H.; Chua, S.; Fu, M.; Ko, S.F.; et al. Early combined treatment with sildenafil and adipose-derived mesenchymal stem cells preserves heart function in rat dilated cardiomyopathy. J. Transl. Med. 2010, 8, 1-16. [CrossRef] [PubMed]

177. Yañez, R.; Lamana, M.L.; García-Castro, J.; Colmenero, I.; Ramírez, M.; Bueren, J.A. Adipose Tissue-Derived Mesenchymal Stem Cells Have In Vivo Immunosuppressive Properties Applicable for the Control of the Graft-versus-Host Disease. Stem Cells 2006, 24, 2582-2591. [CrossRef] [PubMed]

178. Orabi, H.; Lin, G.; Ferretti, L.; Lin, C.S.; Lue, T.F. Scaffoldless Tissue Engineering of Stem Cell Derived Cavernous Tissue for Treatment of Erectile Function. J. Sex. Med. 2012, 9, 1522-1534. [CrossRef]

179. Urrutia, D.N.; Caviedes, P.; Mardones, R.; Minguell, J.J.; Vega-Letter, A.M.; Jofre, C.M. Comparative study of the neural differentiation capacity of mesenchymal stromal cells from different tissue sources: An approach for their use in neural regeneration therapies. PLoS ONE 2019, 14, e0213032. [CrossRef]

180. Dos Santos, A.; Balayan, A.; Funderburgh, M.L.; Ngo, J.; Funderburgh, J.L.; Deng, S.D. Differentiation capacity of human mesenchymal stem cells into keratocyte lineage. Investig. Ophthalmol. Vis. Sci. 2019, 60, 3013-3023. [CrossRef]

181. Ben-David, U.; Benvenisty, N. The tumorigenicity of human embryonic and induced pluripotent stem cells. Nat. Rev. Cancer 2011, 11, 268-277. [CrossRef]

182. Yasuda, S.; Kusakawa, S.; Kuroda, T.; Miura, T.; Tano, K.; Takada, N.; Matsuyama, S.; Matsuyama, A.; Nasu, M.; Umezawa, A.; et al. Tumorigenicity-associated characteristics of human iPS cell lines. PLoS ONE 2018, 13, e0205022. [CrossRef] [PubMed]

183. Papapetrou, E.P. Patient-derived induced pluripotent stem cells in cancer research and precision oncology. Nat. Med. 2016, 22, 1392-1401. [CrossRef] [PubMed]

184. Blum, B.; Benvenisty, N. The Tumorigenicity of Human Embryonic Stem Cells. Adv. Cancer Res. 2008, 100, 133-158. [PubMed]

185. Baker, M. Unregulated stem cell transplant causes tumours. Nat. Rep. Stem Cells 2009. [CrossRef]

186. Liu, Z.; Tang, Y.; Lü, S.; Zhou, J.; Du, Z.; Duan, C.; Li, Z.; Wang, C. The tumourigenicity of iPS cells and their differentiated derivates. J. Cell. Mol. Med. 2013, 17, 782-791. [CrossRef]

187. Xu, H.; Wang, B.; Ono, M.; Kagita, A.; Fujii, K.; Sasakawa, N.; Ueda, T.; Gee, P.; Nishikawa, M.; Nomura, M.; et al. Targeted Disruption of HLA Genes via CRISPR-Cas9 Generates iPSCs with Enhanced Immune Compatibility. Cell Stem Cell 2019, 24, 566-578. [CrossRef]

188. Elliott, M.J.; De Coppi, P.; Speggiorin, S.; Roebuck, D.; Butler, C.R.; Samuel, E.; Crowley, C.; McLaren, C.; Fierens, A.; Vondrys, D.; et al. Stem-cell-based, tissue engineered tracheal replacement in a child: A 2-year follow-up study. Lancet 2012, 380, 994-1000. [CrossRef]

189. Griffith, L.G.; Swartz, M.A. Capturing complex 3D tissue physiology in vitro. Nat. Rev. Mol. Cell Biol. 2006, 7, 211-224. [CrossRef]

190. Maby-El Hajjami, H.; Petrova, T.V. Developmental and pathological lymphangiogenesis: From models to human disease. Histochem. Cell Biol. 2008, 130, 1063-1078. [CrossRef]

191. Li, G.N.; Hoffman-Kim, D. Tissue-engineered platforms of axon guidance. Tissue Eng. Part B Rev. 2008, 14, 33-51. [CrossRef]

192. Zhang, H.; Wei, Y.T.; Tsang, K.S.; Sun, C.R.; Li, J.; Huang, H.; Cui, F.Z.; An, Y.H. Implantation of neural stem cells embedded in hyaluronic acid and collagen composite conduit promotes regeneration in a rabbit facial nerve injury model. J. Transl. Med. 2008, 6, 67. [CrossRef] [PubMed]

193. Ichihara, S.; Inada, Y.; Nakamura, T. Artificial nerve tubes and their application for repair of peripheral nerve injury: An update of current concepts. Injury 2008, 39, 29-39. [CrossRef] [PubMed]

194. Tiruvannamalai-Annamalai, R.; Armant, D.R.; Matthew, H.W.T. A glycosaminoglycan based, modular tissue scaffold system for rapid assembly of perfusable, high cell density, engineered tissues. PLoS ONE 2014, 9, e84287. [CrossRef] [PubMed]

195. Nakayama, K.H.; Batchelder, C.A.; Lee, C.I.; Tarantal, A.F. Renal tissue engineering with decellularized rhesus monkey kidneys: Age-related differences. Tissue Eng. Part A 2011, 17, 2891-2901. [CrossRef] 
196. Kropp, C.; Massai, D.; Zweigerdt, R. Progress and challenges in large-scale expansion of human pluripotent stem cells. Process Biochem. 2017, 59, 244-254. [CrossRef]

197. Tirziu, D.; Giordano, F.J.; Simons, M. Cell communications in the heart. Circulation 2010, 122, $928-937$. [CrossRef]

198. Park, K.-M.; Hussein, K.H.; Hong, S.-H.; Ahn, C.; Yang, S.-R.; Park, S.-M.; Kweon, O.-K.; Kim, B.-M.; Woo, H.-M. Decellularized Liver Extracellular Matrix as Promising Tools for Transplantable Bioengineered Liver Promotes Hepatic Lineage Commitments of Induced Pluripotent Stem Cells. Tissue Eng. Part A 2016, 22, 449-460. [CrossRef]

199. FDA. Tissue \& Tissue Products. Available online: https://www.fda.gov/vaccines-blood-biologics/tissuetissue-products (accessed on 19 April 2020).

200. FDA. CFR—Code of Federal Regulations Title 21. Available online: https://www.accessdata.fda.gov/scripts/ cdrh/cfdocs/cfcfr/CFRSearch.cfm?CFRPart=1270 (accessed on 19 April 2020).

201. FDA. Premarket Approval (PMA). Available online: https://www.fda.gov/medical-devices/premarketsubmissions/premarket-approval-pma (accessed on 19 April 2020).

C 2020 by the authors. Licensee MDPI, Basel, Switzerland. This article is an open access article distributed under the terms and conditions of the Creative Commons Attribution (CC BY) license (http://creativecommons.org/licenses/by/4.0/). 